\title{
DDX3 Modulates Neurite Development via Translationally Activating an RNA Regulon Involved in Racl Activation
}

\author{
Hung-Hsi Chen, Hsin-I Yu, and $\odot$ Woan-Yuh Tarn \\ Institute of Biomedical Sciences, Academia Sinica, Taipei 11529, Taiwan
}

The RNA helicase DDX3 is a component of neuronal granules, and its gene mutations are linked to intellectual disability (ID). Here we demonstrate that DDX3 depletion in neurons impairs neurite development by downregulating Racl level and activation. Moreover, DDX3 activates the translation of functionally coherent mRNAs involved in Rac1 activation including Rac1. Among the DDX3 regulon, Prkaca encodes the catalytic subunit of PKA, a potential activator of Rac1 in neurons. DDX3-modulated PKAc $\alpha$ and Rac1 expression tunes the strength of PKA-Racl signaling and thereby contributes to neurite outgrowth and dendritic spine formation. Inhibition of DDX3 activity or expression in neonatal mice impaired dendritic outgrowth and spine formation of hippocampal neurons, echoing neuronal deficits underling DDX3 mutation-associated ID. Finally, we provide evidence that DDX3 activates local protein synthesis through a 5' UTR-dependent mechanism in neurons. The novel DDX3 regulon may conduct a spatial and temporal control of Rac1 signaling to regulate neurite development.

Key words: dendritic spines; neurite outgrowth; PKA signaling; RNA helicase; translational control

\section{Significance Statement}

$D D X 3 X$ mutations are linked to intellectual disability (ID). We provide first evidence that DDX3 is required for neurite outgrowth and dendritic spine formation in vitro and in vivo. We identified a DDX3 regulon constituting functionally cohesive mRNAs involved in Rac1 signaling, which contributes to DDX3-modulated neurite development. Inhibition or ablation of DDX3 in vivo shortened neurite lengths and impaired dendritic spine formation in hippocampal neurons, reflecting the prevalence of IDassociated $D D X 3 X$ mutations in the helicase domain. Mechanistically, DDX3 activates local protein synthesis of mRNAs sharing similar 5' UTR structures and therefore controls Racl signaling strength in neurites.

\section{Introduction}

DDX3, as a member of the DEAD/H box helicase family, participates in several steps of gene expression, from transcription, pre-mRNA processing, and mRNA export to translation (Sharma and Jankowsky, 2014). DDX3 also functions as a cellular signaling factor and contributes to antiviral innate immunity pathways (Soto-Rifo and Ohlmann, 2013; Ariumi, 2014). Although mammalian DDX3 has multiple cellular functions, the role of DDX3 orthologs in translational control is evolutionarily conserved (Soto-Rifo and Ohlmann, 2013; Ariumi, 2014). One

\footnotetext{
Received Dec. 23, 2015; revised July 28, 2016; accepted Aug. 1, 2016.

Author contributions: H.-H.C., H.-I.Y., and W.-Y.T. designed research; H.-H.C. and H.-I.Y. performed research; H.-H.C. and H.-I.Y. analyzed data; H.-H.C. and W.-Y.T. wrote the paper.

This work was supported by Grant IBMS-CRC104-P01 from the Institute of Biomedical Sciences, Academia Sinica. We thank James C.-K. Shen and Mi-Hua Tao for providing vectors and producing AAV as well as Yi-Shuian Huang and Guey-Shin Wang for rat neurons. We also thank the Core Facility of the Institute of Biomedical Sciences, Academia Sinica, for their technical assistance.

The authors declare no competing financial interests.

Correspondence should be addressed to Woan-Yuh Tarn, Institute of Biomedical Sciences, Academia Sinica, 128 Academia Road, Section 2, Nankang, Taipei 11529, Taiwan. E-mail: wtarn@ibms.sinica.edu.tw.

DOI:10.1523/JNEUROSCI.4603-15.2016

Copyright $\odot 2016$ the authors $\quad 0270-6474 / 16 / 369792-13 \$ 15.00 / 0$
}

such ortholog, yeast Ded1p, is an essential protein that functions as a translation initiation factor that facilitates ribosome scanning of mRNAs (Iost et al., 1999; Yang and Jankowsky, 2005). Mammalian DDX3 also interacts with several initiation factors, such as components of eIF3 and eIF4F, whereby it facilitates $40 \mathrm{~S}$ ribosome scanning of the $5^{\prime}$ untranslated region (UTR) of mRNAs and/or promotes $80 \mathrm{~S}$ ribosome assembly (Lee et al., 2008; SotoRifo et al., 2012). Several lines of evidence indicate that DDX3 may regulate the translation of selective mRNAs that contain a structured 5' UTR (Lai et al., 2008; Soto-Rifo et al., 2012). DDX3 mediates certain cellular functions through its activity in translational control. For example, DDX3 is required for efficient translation of cyclin E1 and Rac1 mRNAs, whereby it participates in cell cycle progression and cell migration (Lai et al., 2008; Chen et al., 2015). Additional activities of DDX3 also contribute to its various cellular functions (Soto-Rifo and Ohlmann, 2013; Ariumi, 2014).

Localized protein expression is important for the development and function of neuronal cells, such as directional growth of axons and synaptic plasticity of dendrites (Sinnamon and Czaplinski, 2011). Local protein synthesis involves mRNA trafficking and trans- 
lation control and is modulated by neuronal activity. Translocation of dendrite-specific mRNAs occurs in RNA granules that contain various RNA binding proteins linked to the cytoskeleton, which mediates their dynamic properties (Kiebler and Bassell, 2006; LiuYesucevitz et al., 2011). Translation of those mRNAs is generally silent during transport, whereas RNA binding proteins function coordinately to regulate local translation at synapses. The most extensively studied RNA binding proteins include familial mental retardation protein (FMRP), hnRNP A2, and the microRNP effector Ago2. Zipcode-binding protein 1 regulates $\beta$-actin mRNA transport and translation and is thus important for dendrite formation in hippocampal neurons. DDX3 has also been detected in kinesinassociated RNA granules, but it is dispensable for the transport of calcium/calmodulin-dependent protein kinase II (CaMKII) $\alpha$ subunit mRNA (Kanai et al., 2004). The possibility that DDX3 plays a role in local translation activation in neurons remains to be studied (Elvira et al., 2006). Furthermore, DDX3 mutations are associated with developmental disorders and sporadic and unexplained intellectual deficits (Rauch et al., 2012; Deciphering Developmental Disorders Study, 2015; Snijders Blok et al., 2015). We therefore explored the functions of DDX3 in neuronal development.

DDX3 is essential for efficient expression of Rac1, which hence contributes to cell adhesion and motility control in transformed and cancerous cells (Chen et al., 2015). Rac1, as well as other Rho GTPases, regulates actin dynamics in a range of cellular processes including neuronal morphogenesis (Kuhn et al., 2000; Heasman and Ridley, 2008). We initially observed that neurite outgrowth is compromised in DDX3-depleted cortical neurons and neuroblastoma Neuro2A (N2A) cells, which led us to investigate whether DDX3 regulates Rac1 mRNA metabolism in neurons and thereby affects neural development.

Here we report that DDX3 depletion abolishes Rac1 activation in neuronal cells. Racl activation is required for neurite outgrowth and is modulated by upstream signaling activities (Govek et al., 2005). We found that Prkaca, which encodes the catalytic subunit of protein kinase A (PKAc $\alpha)$, is a potential translational target of DDX3. PKA can mediate cAMP signaling-enhanced neurite outgrowth by activating Rac1 (Goto et al., 2011). We thus tested whether DDX3 regulates the expression/metabolism of mRNAs that act coordinately in neuronal development.

\section{Materials and Methods}

Plasmids and siRNAs. pcDNA-FLAG-DDX3, pcDNA-FLAG-DDX3 (S382L), pcDNA-Rac1, pcDNA-Rac1N17, and pcDNA-Rac1V12 were used previously (Chen et al., 2015). pEGFP-actin was provided by Y.-P. Hsueh (Institute of Molecular Biology, Academia Sinica, Taipei, Taiwan). The Rac1 5' UTR-Myr-dGFP-MS2 $\times 10$ was constructed in pcDNA3.1 (Addgene), in which myristoylated and destabilized GFP (Myr-dGFP) was amplified from phSyn-myr-d1GFP, a gift from B. Xu (Department of Pharmacology, Georgetown University, Washington, DC). The RFP-NLS-MCP coding sequence was constructed and placed in pEGFP-C1 (Addgene) to replace EGFP with a red fluorescent protein (RFP) and MS2 coat protein (MCP) fusion protein with an SV40 nuclear localization signal (NLS). Stealth RNAi siRNA Negative Control Lo GC (Thermo Fisher Scientific) served as the control siRNA (siC). The DDX3-specific siRNAs MSS236324 (siD\#1), MSS236325 (siD\#2), and MSS236326 (siD\#3) were purchased from Thermo Fisher Scientific. One scramble (shC target sequence, GCGCTTC TACCAAATACACTTGATA) and two DDX3-specific (sh1, CCTAGAC CTGAACTCTTCAGATAAT; sh2, GGAAACATTGAGCTTACTCG TTATA) shRNAs were cloned into the pAAVEMBL-CB-EGFP vector for adeno-associated virus (AAV) production (Chen et al., 2009).

Antibodies. Antibodies used included mouse monoclonal antibodies against actin (catalog \#sc-8432), $\alpha$-tubulin (catalog \#sc-5286), and DDX3 (catalog \#sc-265768; all from Santa Cruz Biotechnology), GFP (catalog \#A-11120, Thermo Fisher Scientific), hnRNP Q1 (AnaSpec), and Rac1 (catalog \#23A8, EMD Millipore); rabbit polyclonal antibodies against $\beta$-catenin (catalog \#sc-7199), DDX3 (catalog \#sc-98711), FMRP (catalog \#sc-28739), Rac1 (catalog \#sc-217; all from Santa Cruz Biotechnology), phospho-(Ser/Thr) PKA substrate (Cell Signaling Technology), and GFP (catalog \#A-11122, Thermo Fisher Scientific); and goat polyclonal antibody against and Tiam2 (catalog \#sc-13303, Santa Cruz Biotechnology). Secondary antibodies for immunofluorescence and immunoblotting were purchased from Thermo Fisher Scientific and GE Healthcare Life Sciences, respectively.

Cell culture and transfection. Murine N2A cells and primary neurons were cultured and transfected as described previously (Chen et al., 2012). To induce neurite outgrowth in N2A cells, cells were cultured in serum-free medium or growth medium containing $10 \mu \mathrm{M}$ forskolin (Sigma-Aldrich). To inhibit PKA activity, $20 \mu \mathrm{M}$ H89 (Cell Signaling Technology) was used. To establish stably transfected N2A cells, cells transfected with pcDNA or pcDNA-FLAG-DDX3 (to express FLAG-tagged DDX3) were selected in G418 (InvivoGen) for 2 weeks and then serially diluted into a 96-well culture plate for 2 more weeks of culture. Cells from single colonies were expanded to assess FLAG-DDX3 expression. For transfection of cells with siRNA, 80 pmol siRNA was used for a $3.5 \mathrm{~cm}$ plate in all the experiments except that 20 pmol siRNA was used to partially preserve the neurite outgrowth ability of N2A cells in Figure 7B. To achieve high knockdown efficiency in primary cortical neuron (see Fig. 5C), Magnetophectamine-mediated transfection was performed per the manufacturer's instruction (OZ Biosciences).

Indirect immunofluorescence, confocal microscopy, and image analysis. Immunofluorescence staining, confocal microscopy, and image analysis were performed as described previously (Chen et al., 2012). In N2A cells, neurite-bearing cells were defined as cells harboring neurites with total length longer than twice the cell diameter. In primary neurons, the average length of major neurites and dendrites (labeled as neurite length and dendrite length, respectively) was measured in the GFP- and MPA2-positive neurons with at least one neurite longer than $30 \mu \mathrm{m}$.

Immunoblotting, immunoprecipitation, and RNA immunoprecipitation. Immunoblotting, immunoprecipitation, and RNA immunoprecipitation were performed as described previously (Chen et al., 2012). Protein intensity on immunoblots was quantified using densitometry.

Racl activation analysis. Pull-down of GTP-bound (active) Racl was performed by using an Rac1/Cdc42 Activation Assay kit (EMD Millipore). Briefly, cultured cells with $\sim 80 \%$ confluency were lysed and incubated with $10 \mu \mathrm{g}$ of PAK1 Rac/Cdc42 (p21) binding domain (PBD) agarose at $4^{\circ} \mathrm{C}$ for $1 \mathrm{~h}$. Beads were washed thoroughly and suspended in Laemmli reducing sample buffer for SDS-PAGE and immunoblotting.

Polysome fractionation. Sucrose density gradient fractionation (linear gradient, 15-40\% sucrose) was performed as described previously (Lai et al., 2010; Chen et al., 2015). RNA in each of fractions 3-6 and of 8-18 was extracted with Trizol LS Reagent (Thermo Fisher Scientific) and pooled as light and heavy fractions, respectively.

In vivo translation assay. The in vivo translation assay was performed as described previously (Chen et al., 2015).

$R T-q P C R$ and $R T-P C R$. Reverse transcription (RT), quantitative PCR (qPCR), and PCR were performed as described previously (Chen et al., 2015).

Fractionation of neurite and soma. Neurite and soma fractions were collected as described previously (Chen et al., 2012) with minor modifications. Briefly, $5 \times 10^{5}$ primary cortical neurons and $2 \times 10^{5} \mathrm{~N} 2 \mathrm{~A}$ cells were seeded in $24 \mathrm{~mm}$ transwell polyethylene tetraphthalate membrane inserts ( $1 \mu \mathrm{m}$ pore size; EMD Millipore) with or without $1 \mathrm{mg} / \mathrm{ml}$ of poly-D-lysine (Sigma-Aldrich) coating, respectively. Cortical neurons were cultured in Neurobasal medium supplemented with 2\% B-27 supplement (Thermo Fisher Scientific), $0.5 \mathrm{~mm}$ L-glutamine, $100 \mathrm{U} / \mathrm{ml}$ penicillin, and $100 \mathrm{mg} / \mathrm{ml}$ streptomycin for $72 \mathrm{~h}$, and N2A cells were cultured in DMEM medium supplemented with $10 \%$ fetal bovine serum, $2 \mathrm{~mm}$ L-glutamine, $100 \mathrm{U} / \mathrm{ml}$ penicillin, $100 \mathrm{mg} / \mathrm{ml}$ streptomycin, and $10 \mu \mathrm{M}$ forskolin for $24 \mathrm{~h}$. Lysates of neurites (bottom side) and soma (top side) were collected from individual wells, in which the top-side and bottomside membranes were separately precleared with cotton swabs. Culture 
A

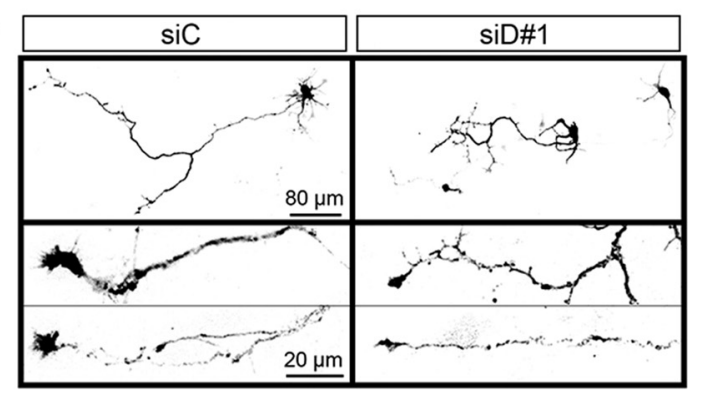

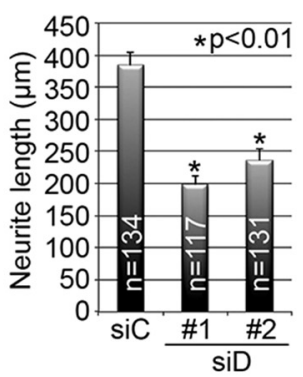

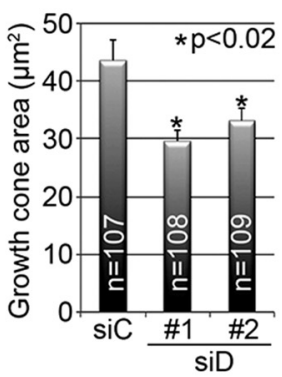

B
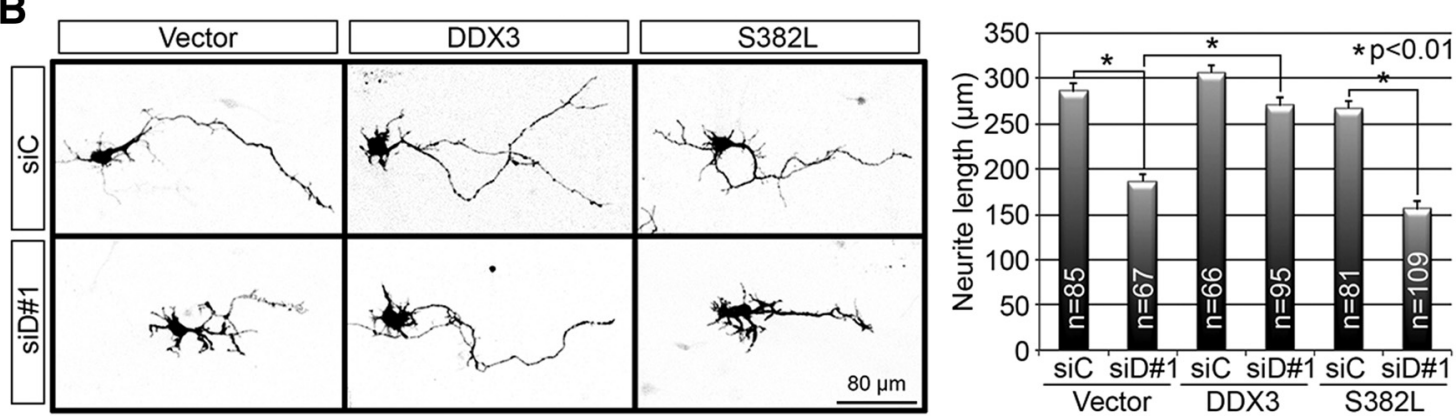

Figure 1. DDX3 is involved in neurite outgrowth. $A$, Primary cortical neurons cotransfected with pEGFP and siRNA at DIV1 and cultured for $2 \mathrm{~d}$, and then stained with anti-GFP. The representative images of whole neurons and growth cones are shown in the left top and bottom panels, respectively. Bar graphs show the averages of the major neurite length and growth cone area. $\boldsymbol{B}$, Primary cortical neurons cotransfected with pEGFP, siRNA, and indicated expression vector at DIV1 for $2 \mathrm{~d}$. Anti-GFP staining was as in $A$. The representative images of neurons are shown on the left. The bar graph shows the averages of the major neurite length. Error bars indicate SE.

medium and supplements were all purchased from Thermo Fisher Scientific.

Fluorescence recovery after photobleaching. Primary cortical neurons were cultured in phenol red-free Neurobasal medium with supplements on $\mu$-slide glass bottoms (ibidi $\mathrm{GmbH}$ ) coated with poly-D-lysine and was transfected with pcDNA-Rac1 5' UTR-Myr-dGFP. Fluorescence recovery after photobleaching (FRAP) of live cells was performed by using a Zeiss LSM780 upright microscope equipped with a humidified $37^{\circ} \mathrm{C}$ chamber with $5 \% \mathrm{CO}_{2}$, and images were captured under a $100 \times$ oilimmersion objective lens. Green fluorescence of neurite terminals/ growth cones was bleached with $100 \%$ laser power for 100 times and then recovered for $10 \mathrm{~min}$ with image capture per $20 \mathrm{~s}$ under $15 \%$ laser power. To inhibit translation, $100 \mu \mathrm{g} / \mathrm{ml}$ cycloheximide (Sigma-Aldrich) was added 30 min prior to FRAP.

Ketorolac treatment of mice. BALB/c mice (purchased from National Applied Research Laboratories, Taipei, Taiwan) were housed in the animal facility of the Institute of Biomedical Sciences (Taipei, Taiwan). Mice were mock injected or injected (intraperitoneally) with $10 \mathrm{mg} / \mathrm{kg}$ ketorolac (Cayman Chemical) at postnatal day 14 (P14), P18, and P22. Mice were killed at P24, and the brains from two males and two females of both control and ketorolac-treated mice were dissected for Golgi staining with the FD Rapid GolgiStain kit (FD NeuroTechnologies). Coronal sections $(140 \mu \mathrm{m})$ cut with a Leica Vibratome VT1000 S were mounted on gelatin-coated microscope slides (FD NeuroTechnologies) for staining. $Z$-stack images of dendrites and dendritic spines of CA1 pyramidal neurons were respectively collected under a Zeiss Axiovert 200M microscope with a $20 \times$ objective lens and a Zeiss LSM780 microscope with a $63 \times$ oil-immersion objective lens.

Intraventricular AAV injection. pAAVEMBL-CB-EGFP-based AAV vectors were used to generate serotype AAV8 in HEK293T cells (Chen et al., 2009). Intracventricular AAV injection of neonatal (P0) BABL/c mice was performed as described previously (Kim et al., 2013). Briefly, each cryoanesthetized mouse was manually injected with $10^{10}$ vector genomes of AAV per ventricle. The surviving mice were killed at P20, and coronal sections $(20 \mu \mathrm{m})$ of the brains from two males and two females of both $\mathrm{AAV}$-shC-injected and AAV-sh1-injected mice were cut with a Leica Cryostat CM3050S and mounted on Silane-coated slides (Muto Pure Chemicals) for GFP and DAPI staining. $Z$-stack images of dendritic spines of CA1 pyramidal neurons were collected under a Zeiss Axiovert $200 \mathrm{M}$ microscope with a $20 \times$ objective lens and a Zeiss LSM780 microscope with a $40 \times$ water-immersion objective lens.

Statistical analysis. In all experiments shown in all figures, the average values and corresponding SDs were obtained from at least three independent experiments. The number of examined neurons is indicated in the figures.

\section{Results}

\section{DDX3 is essential for neurite outgrowth}

To assess the neuronal function of DDX3, we used siRNAs to deplete DDX3 in cultured rat embryonic cortical neurons. Immunostaining demonstrated that a DDX3-targeting siRNA (abbreviated as siD, siD\#1 in Fig. 1A) could efficiently deplete DDX3 in transfected neurons (data not shown). DDX3 depletion decreased neurite length and growth cone area by, respectively, $\sim 50$ and $\sim 25 \%$ in primary cortical neurons (Fig. $1 A$ ), suggesting that DDX3 may have a role in cytoskeletal rearrangements. Next, to evaluate whether such a function of DDX3 may involve its RNA helicase activity, we ectopically expressed the wild-type or helicase-defective (S382L) DDX3 (Yedavalli et al., 2004) in DDX3-depleted cortical neurons. The result showed that only the wild type was able to rescue neurite outgrowth in DDX3-depleted cells (Fig. 1B), suggesting that DDX3 helicase activity may participate in neurite outgrowth.

Next, we characterized the role of DDX3 in neurite outgrowth of N2A cells. Compared with controls, siD-transfected $\mathrm{N} 2 \mathrm{~A}$ cells failed to generate neurite-like processes under serum-free conditions (Fig. 2A). Ectopically expressed wildtype but not S382L DDX3 could rescue neurite outgrowth in DDX3-depleted N2A cells (Fig. 2A), indicating that the RNA helicase activity of DDX3 is also essential for neurite outgrowth in N2A cells. 

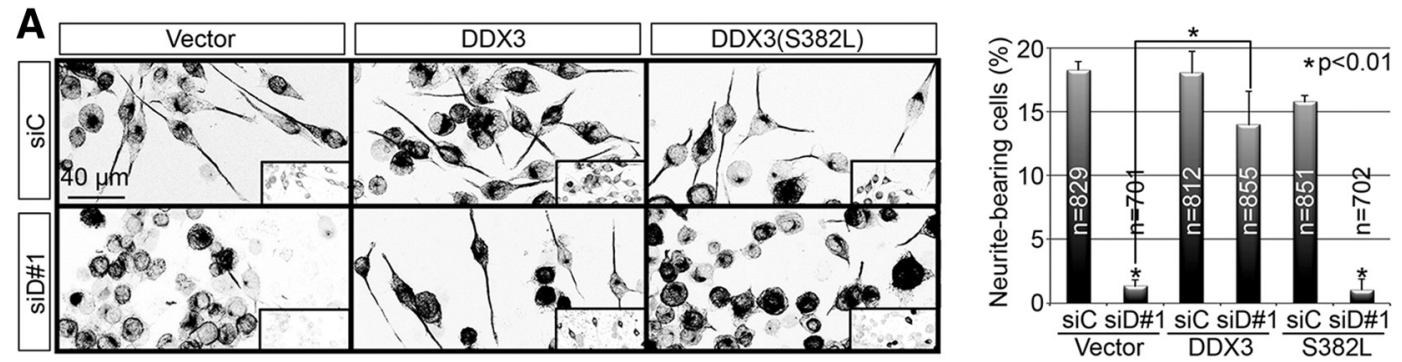

B
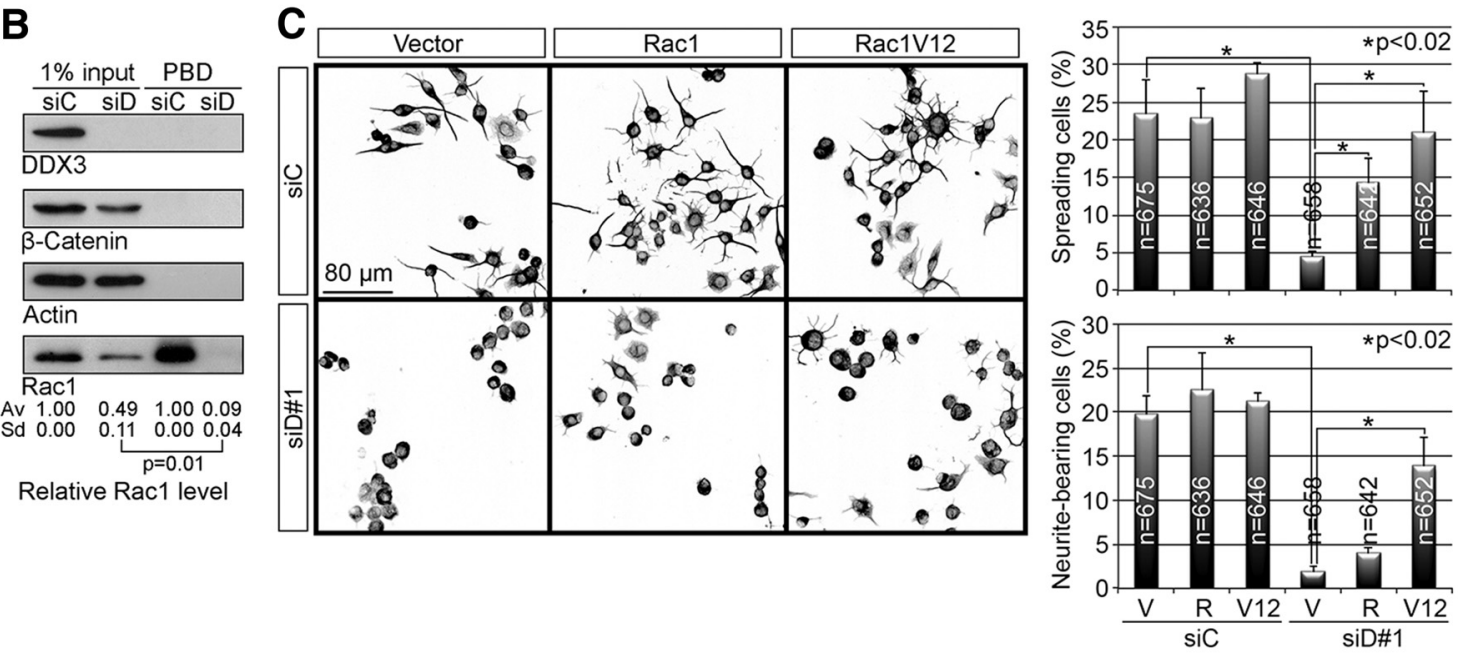

Figure 2. Rac1 activity is required for DDX3-modulated neurite outgrowth. $A$, N2A cells were cotransfected with siRNA (siC or siD\#1) and the empty or DDX3 (wild-type or S382L mutant) expression vector. The left panel shows immunofluorescence staining for $\alpha$-tubulin and DDX3 (insets). The bar graph shows the percentages of neurite-bearing cells. $\boldsymbol{B}$, Active Rac1 was pulled down from lysates of siRNA-transfected N2A cells using PAK-PBD beads. Immunoblots show DDX3, $\beta$-catenin, actin, and Rac1 in the input and resin-bound fractions. The relative levels of activated Rac1 are shown below the blots. C, N2A cells were cotransfected with the indicated siRNA and an empty or an Rac1 (wild-type or V12 mutant) expression vector. Immunofluorescence staining was performed for $\alpha$-tubulin. The bar graphs show the percentages of spreading and neurite-bearing cells. Error bars indicate SE.

\section{Activated Rac1 is responsible for DDX3-modulated neurite outgrowth}

We reported previously that DDX3 promotes the translation of Rac1 mRNA, which is essential for $\mathrm{N} 2 \mathrm{~A}$ cell migration in the serum-containing medium (Chen et al., 2015). Racl is also involved in neurite outgrowth and growth cone dynamics (Woo and Gomez, 2006). We therefore examined Racl expression in DDX3-depleted N2A cells under serum-free conditions. Immunoblotting revealed that DDX3 knockdown reduced the level of Racl protein by $\sim 50 \%$ (Fig. $2 B$, Racl in input). Ectopic expression of Racl could rescue the cell-spreading phenotype of DDX3depleted N2A cells, as reported previously (Chen et al., 2015), but was unable to restore neurite outgrowth (Fig. 2C, bar graphs, siD\#1, R). Nevertheless, overexpression of constitutively active Rac1 (Rac1V12) could rescue both cell spreading and neurite outgrowth of DDX3 knockdown cells (Fig. 2C, siD\#1, Rac1V12). Therefore, DDX3 may regulate not only the level of Rac1, but also its activity in neurite outgrowth.

To test our conjecture that DDX3 also modulates Rac1 activity, we estimated the level of active Rac1 in DDX3 knockdown cells. A pull-down assay using glutathione $S$-transferase fused to the Rac/Cdc42 (p21) binding domain of p21-activated kinase (PAK) as bait showed that the level of active Rac1 was reduced to $\sim 10 \%$ of that of the control (Fig. $2 B$, Rac1 in PBD), suggesting that DDX3 is also essential for Rac1 activation.

\section{DDX3 is required for both PKAc $\alpha$ and Rac1 protein expression}

To explore the mechanism by which DDX3 activates Rac1, we analyzed previously identified translational targets of DDX3 (Lai et al., 2010) using the Database for Annotation, Visualization and Integrated Discovery (http://david.abcc.ncifcrf.gov/). This analysis detected several upstream activators of Rac1, including signaling kinases, growth factors, and receptors (Fig. 3A). We then performed sucrose density gradient sedimentation to analyze the distribution of those mRNAs among polysomes. The result showed that several of these target mRNAs shifted from heavy to light polysomal fractions upon DDX3 knockdown. Besides Rac1, Prkaca exhibited most prominent change among all examined factors (Fig. $3 B$ ). PKA has a variety of cellular functions, including promoting neurite outgrowth through Racl activation (Goto et al., 2011). Therefore, we evaluated whether DDX3 is involved in Rac1 activation via promoting the translation of Prkaca mRNA. Immunoblotting demonstrated that the level of PKAc $\alpha$ decreased by $>60 \%$ upon DDX3 knockdown (Fig. $3 C$ ).

DDX3 can activate the translation of mRNAs with a structured 5' UTR, such as Rac1 (Chen et al., 2015). Interestingly, ClustalW and RNAfold analyses revealed substantial nucleotide sequence identity and structural similarity between the Prkaca and Rac1 5' UTRs (Fig. 3D). We next performed an in vivo translation assay in HeLa cells using a luciferase reporter containing either the Rac1 or Prkaca 5' UTR. DDX3 knockdown significantly decreased the luciferase activity of these two reporters (Fig. $3 E$ ). Moreover, the wild-type but not the helicase-defective DDX3 could restore the activity of both reporters (Fig. $3 E$ ), indicating that the helicase activity of DDX3 is required for translational activation of Racl and Prkaca mRNAs that possibly share common structural features. 
A

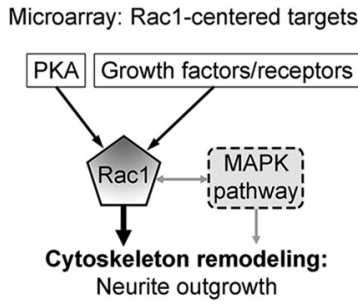

D

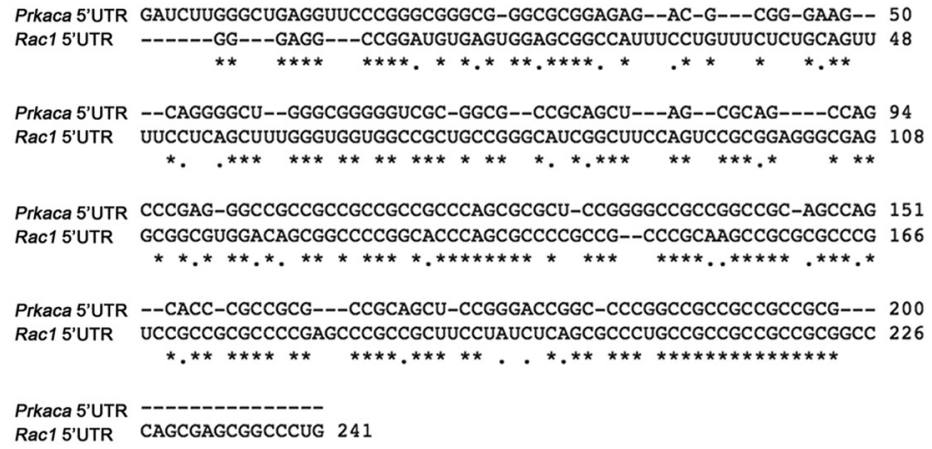

C

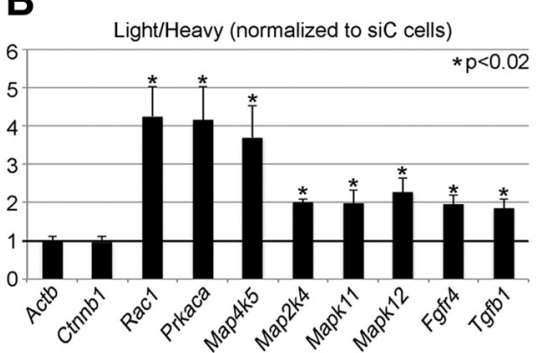

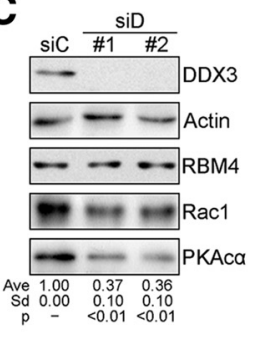

E

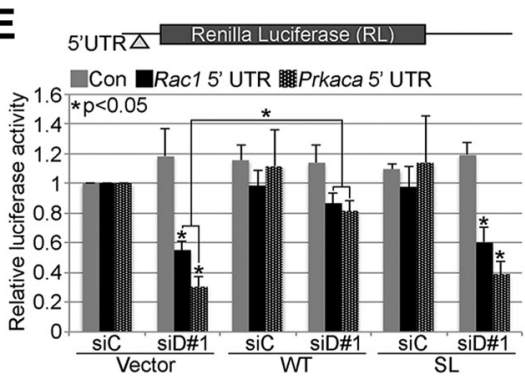

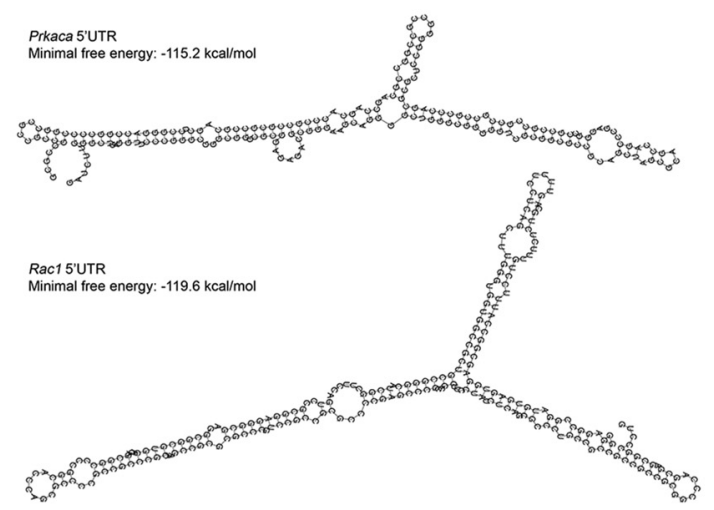

Figure 3. The targets of DDX3 include a set of mRNAs involved in Rac1 activation. $\boldsymbol{A}$, The diagram shows a set of potential DDX3 target mRNAs (Lai et al., 2010 ) that may be involved in Rac1 activation. $\boldsymbol{B}$, RNAs from pooled light and heavy polysome fractions were subjected to RT-qPCR using the indicated primers. The bar graph shows the light/heavy ratio for each gene that was normalized to Actb. C, Immunoblotting was performed to detect the indicated proteins in siC- or siD-transfected N2A cells. The relative levels of PKAc $\alpha$ are indicated below the blots. $\boldsymbol{D}$, The alignment and structure prediction were performed using ClustalW and RNAfold, respectively. $\boldsymbol{E}$, HeLa cells were cotransfected with siC or siD\#1 and the empty or DDX3 (wild-type or S382L mutant) expression vector for $48 \mathrm{~h}$ and subsequently transfected for $1 \mathrm{~h}$ with in vitro synthesized Renilla luciferase mRNA containing control, Rac 1 5' UTR, or Prkaca 5' UTR. The bar graph shows the average luciferase activity normalized to the control (siC plus vector). Error bars indicate SE.

\section{DDX3-modulated neurite outgrowth involves the \\ PKA-Racl pathway}

Based on our results, we hypothesized that DDX3 promotes neurite outgrowth by enhancing the PKA-Racl signaling pathway. To test this possibility, we took advantage of forskolin-induced neurite outgrowth. As reported previously (Yusta et al., 1988), we observed neurite outgrowth of forskolin-treated N2A cells, which could be disrupted by the PKA inhibitor H89, indicating that forskolin acted specifically through PKA (Fig. 4A). Moreover, the GST-PBD pull-down assay revealed that the level of activated Racl increased by more than threefold upon forskolin treatment, and this increase was abolished by further addition of H89, suggesting that forskolin induced Racl activation via PKA (Fig. 4B).

To investigate whether Racl activation is essential for neurite outgrowth in forskolin-treated cells, we ectopically expressed a dominant-negative Rac1 mutant, Rac1N17, which disrupts endogenous Racl activity (Heasman and Ridley, 2008). Indeed, Rac1N17 almost completely abolished forskolin-induced N2A neurite outgrowth (Fig. 4C), supporting the essential role of activated PKA-Rac1 signaling. Moreover, both forskolinpromoted neurite outgrowth and Racl activation were largely compromised in DDX3-depleted N2A cells (Fig. 4D), suggesting that DDX3 plays a critical role in the PKA-Racl signaling axis in neuronal cells. Next, we overexpressed PKAc $\alpha$ and/or Rac1 in mock or DDX3-depleted N2A cells under serum-supplemented conditions. PKAc $\alpha$ overexpression induced neurite outgrowth in N2A cells, as observed in forskolin treatment, while such an effect was abolished by DDX3 knockdown (Fig. 4E-G). In contrast, overexpression of both PKAc $\alpha$ and Racl or Rac1V12 alone could still induce neurite outgrowth in DDX3 knockdown cells (Fig. $4 E-G)$, indicating that DDX3 is essentially involved in PKA-Rac1 signaling-mediated neurite outgrowth in N2A cells. It has been reported that PKA phosphorylates Tiam2, and hence activates Racl and induces neurite outgrowth in PC12D cells (Goto et al., 2011). Using anti-phospho-PKA substrate antibodies, we observed that the level of phosphorylated Tiam2 was indeed increased in forskolin-treated or PKAc $\alpha$-overexpressing N2A cells, indicating that PKAc $\alpha$ may activate Rac1 through Tiam2 (Fig. 4H)

Next, we established two lines of N2A cells (N2A/DDX3) that ectopically expressed FLAG-tagged DDX3 at different levels. Immunoblotting revealed that the upregulated level of Racl and PKAc $\alpha$ correlated well with the level of FLAG-DDX3 (Fig. 4I). Compared with mock cells, a greater fraction of N2A/DDX3 cells generated neurites after induction with forskolin (Fig. 4J), supporting the role of DDX3 in strengthening PKA-Rac1 signaling during neurite outgrowth.

\section{Correlated expression of DDX3, PKAc $\alpha$, and Rac1 in primary neurons}

Racl and PKA modulate not only neurite outgrowth, but also dendrite arborization and dendritic spine formation (Tashiro and Yuste, 2004; Gualdoni et al., 2007; Zhang et al., 2013; Copf, 2014). Therefore, we examined Racl and PKAc $\alpha$ expression in rat embryonic cortical neurons that were cultured up to $20 \mathrm{~d}$ in vitro (DIV). Immunoblotting showed that their protein levels increased in accordance with that of DDX3 from DIV1 to DIV9 (Fig. 5A), whereas their mRNA levels remained essentially constant throughout this period (data not shown). Although DDX3 was subsequently downregulated in the neurons, its expression in dendrites was still notable at later stages (data not shown). Thus, dendritically localized DDX3 might be sufficient to promote Racl and PKAc $\alpha$ protein expression after DIV9 (Fig. 5A, DIV13 and DIV20). To evaluate whether DDX3 is critical for Rac1 and 
A
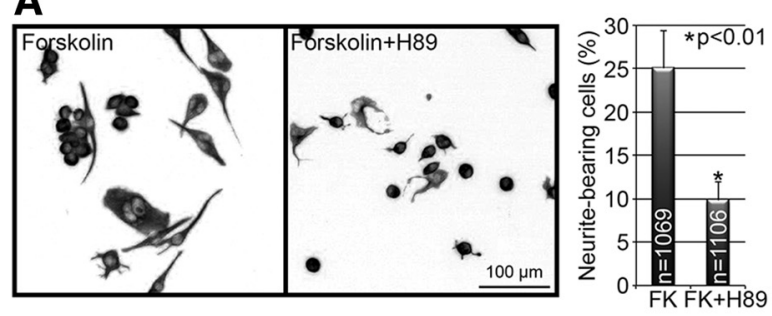

D

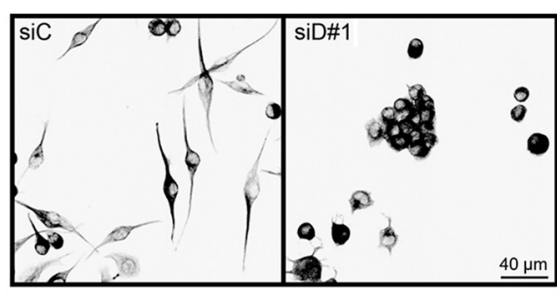

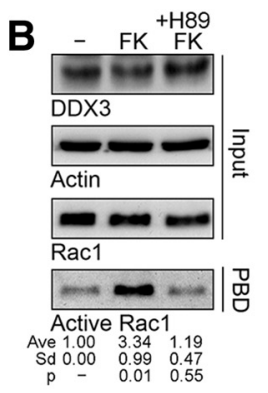

C
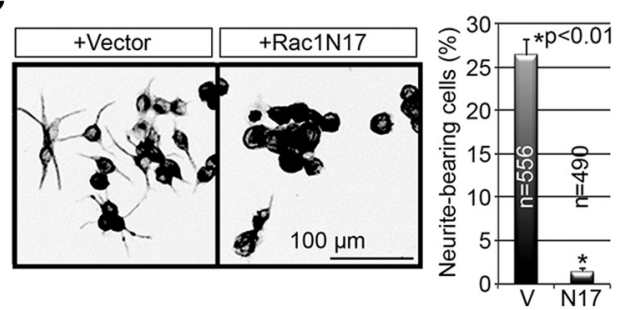

E Con PKA Rac1 PKA+Rac1 Rac1V12

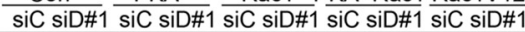

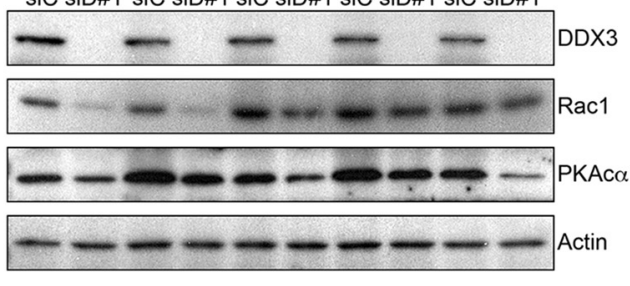

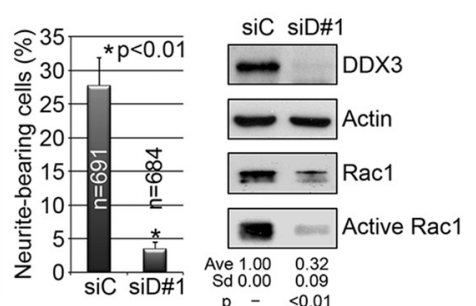

$\mathbf{F}$

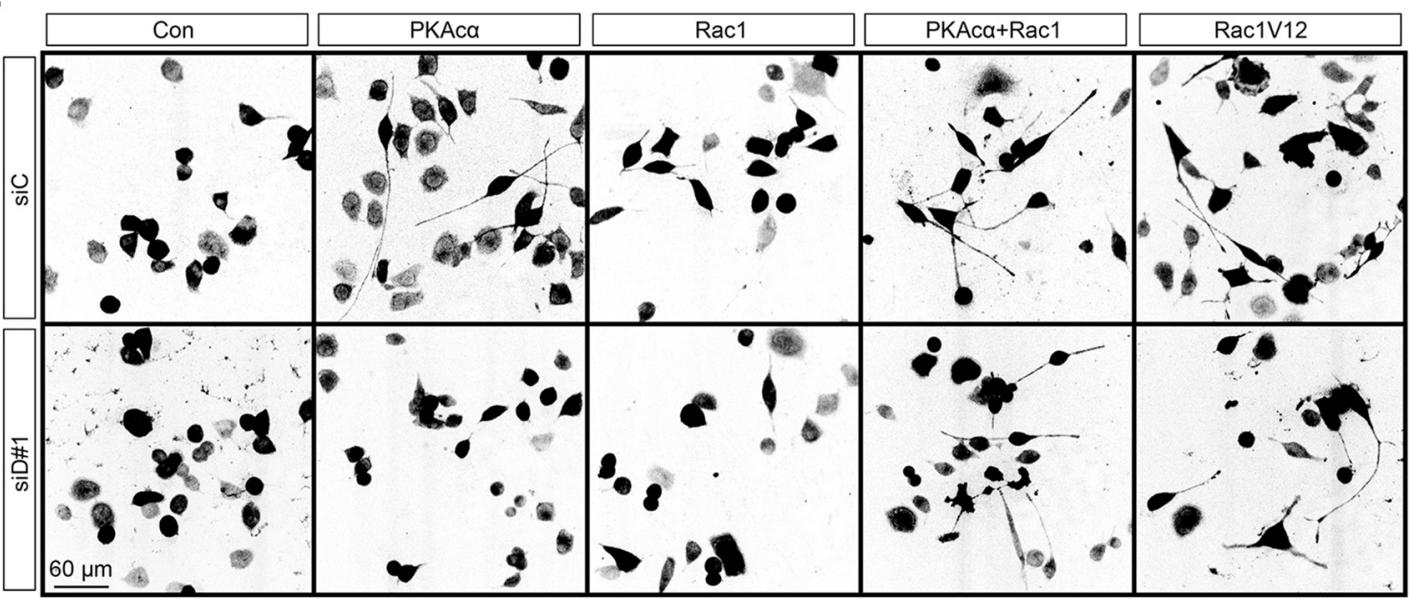

G

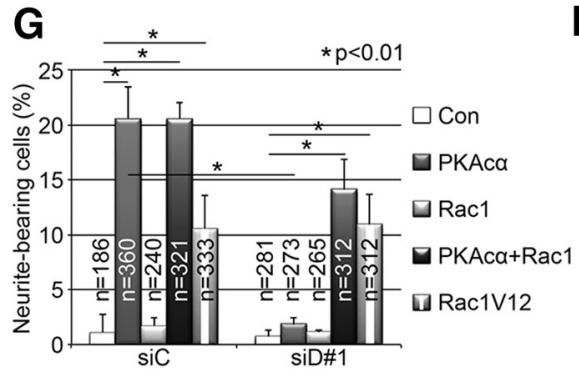

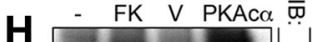

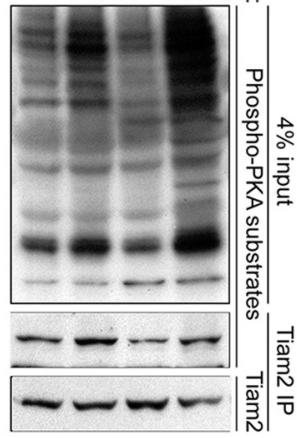

I FLAG-DDX3

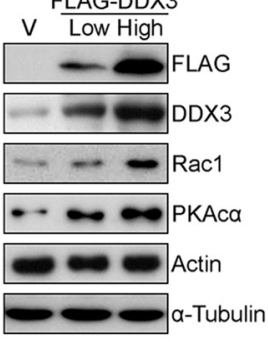

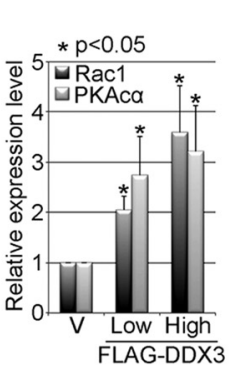

J

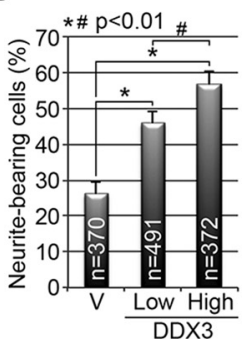

Figure 4. DDX3-modulated PKA-Rac1 signaling is required for neurite outgrowth in N2A cells. $A$, N2A cells were treated with forskolin or forskolin plus $\mathrm{H} 89$ for $24 \mathrm{~h}$, followed by immunofluorescence staining using anti- $\alpha$-tubulin. The bar graph shows quantification of neurite-bearing cells. $B$, Active Rac 1 was pulled down from the lysates of N2A cells that were treated with mock (-), forskolin (FK), or FK plus $\mathrm{H} 89$ for $24 \mathrm{~h}$ by using PAK-PBD beads. Immunoblots show DDX3, actin, and Rac1 in input lysates (top three panels) and precipitated PBD beads (bottom; active Rac1). Relative activated Rac1 levels are indicated below the blots. C, Immunofluorescence for $\alpha$-tubulin and quantification of neurite-bearing cells were performed with N2A cells that were transiently transfected with the control or Rac1N17 expression vector followed by forskolin treatment for $24 \mathrm{~h}$. D, Immunofluorescence staining for $\alpha$-tubulin and quantification of neurite-bearing cells were performed with siC- or siD\#1-transfected N2A cells treated with forskolin for $24 \mathrm{~h}$. E, N2A cells transfected with pEGFP, siC, or siD\#1 and indicated expression vectors were cultured in the growth medium for $24 \mathrm{~h}$. Protein lysates were subjected to immunoblotting analysis for DDX3, Rac1, PKAc $\alpha$, and actin. $F$, The representative images show GFP-positive N2A cells as in $\boldsymbol{E}$. $\boldsymbol{G}$, The bar graph shows the percentages of neurite-bearing cells as in $\boldsymbol{E}$. $\boldsymbol{H}$, N2A cells were mock or forskolin treated or transfected with the control vector (V) or PKAc $\alpha$-expressing vector for $24 \mathrm{~h}$. Tiam2 was immunoprecipitated (IP) from cell lysates and detected by anti-Tiam2 and anti-phospho-PKA substrates. I, Immunoblots of mock (V) or low- or high-level DDX3-expressing stable N2A cells. The bar graph shows relative levels of Rac1 and PKAc $\alpha$.J, Mock or FLAG-DDX3-expressing N2A cells were treated with forskolin for $24 \mathrm{~h}$. The bar graph shows the percentages of neurite-bearing cells. Error bars indicate SE. 
A

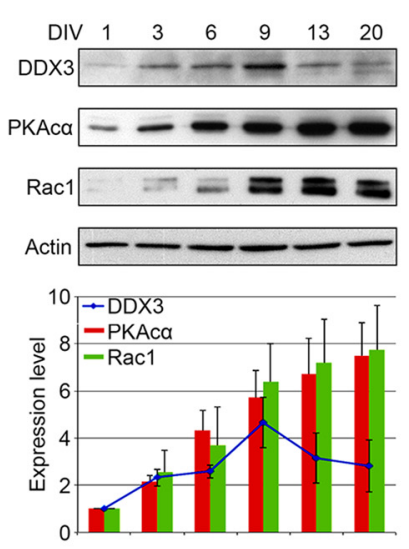

B

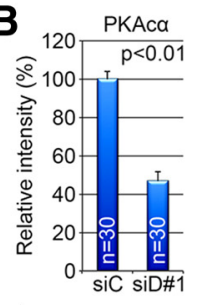

$\mathbf{F}_{\text {. }}$

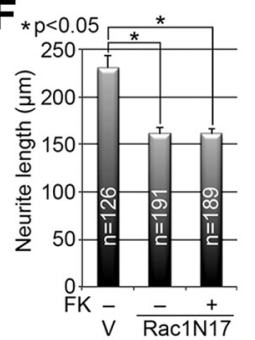

C

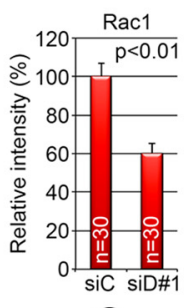

G

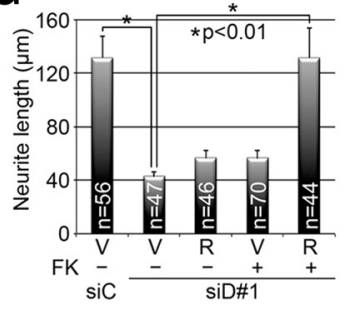

D
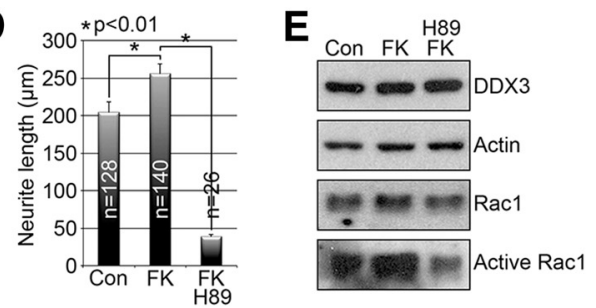

H

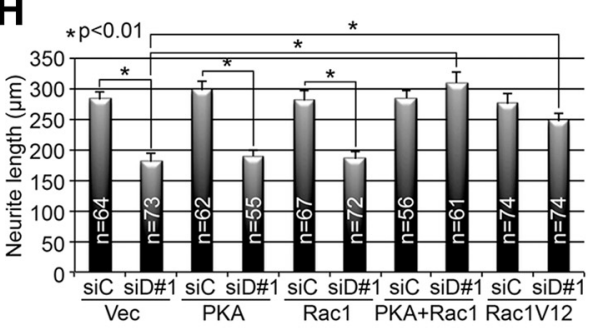

\section{I}
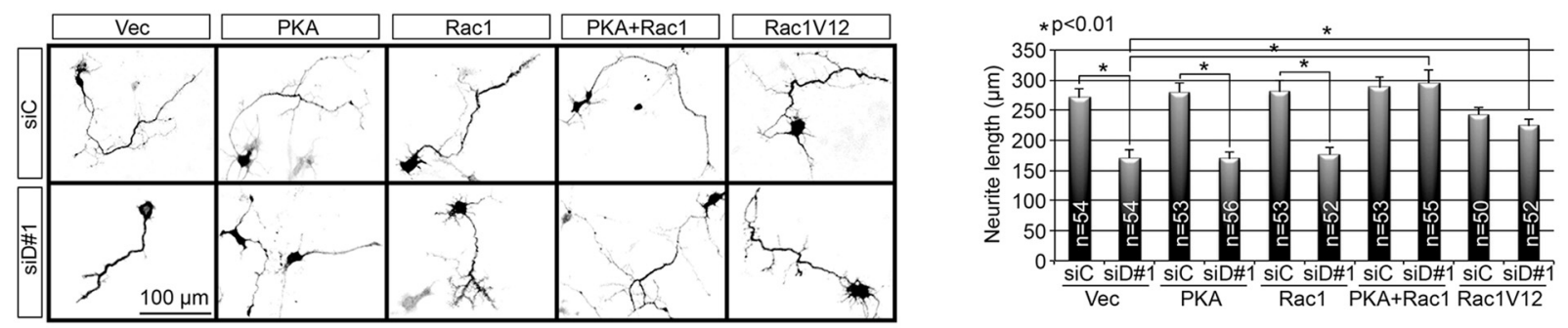

J
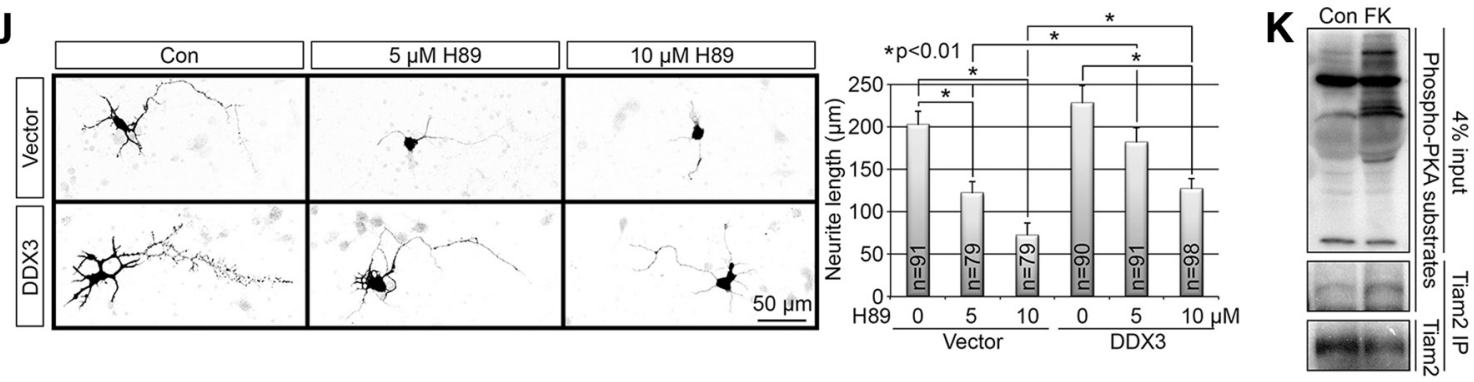

Figure 5. DDX3 modulates neurite outgrowth via PKA-Rac1 signaling in primary cortical neurons. A, Immunoblots show the indicated proteins in primary cortical neurons at DIV1-DIV20. The bar graph shows the expression levels of DDX3 (blue line), PKAc $\alpha$ (red bars), and Rac1 (green bars) at different culture times compared with DIV1. Actin was used for normalization. $\boldsymbol{B}$, Primary cortical neurons cotransfected with pEGFP and siC or siD\#1 were subjected to immunofluorescence staining for GFP and PKAc $\alpha$ or Rac1. Fluorescence intensities of PKAc $\alpha$ (left) and Rac1 (right) in EGFP-positive soma were quantified. C, Lysates from cortical neurons transfected with siC or siD\#1 by Magnetofectamine reagents were subjected to PAK-PBD pull-down. Immunoblots show DDX3, actin, and Rac1 in the input and resin-bound fractions (active Rac1). D, Primary cortical neurons were transfected with the pEGFP vector and then mock treated (Con) or treated with forskolin (FK) or FK plus $\mathrm{H} 89$ for $24 \mathrm{~h}$. The bar graphs in $\mathbf{D}, \boldsymbol{F}, \boldsymbol{H}, \boldsymbol{J}$, and $\boldsymbol{K}$ show average major neurite lengths at DIV1 + 2. E, Lysates of primary cortical neurons treated as in D were subjected to PAK-PBD pull-down. Immunoblots show DDX3, actin, Rac1, and resin-bound active Rac1.F, Primary cortical neurons were transfected with pEGFP and the empty (V) or Rac1N17 vector followed by mock or FK treatment for $24 \mathrm{~h}$. G, Primary cortical neurons were transfected with pEGFP, siRNA (siC or siD\#1), and the empty (V) or Rac1 (R) expression vector in the presence or absence of FK for $24 \mathrm{~h}$. Average major neurite lengths were obtained at DIV0 + 2. H, Primary cortical neurons were transfected with pEGFP, siRNA (siC or siD\#1), and the empty (Vec), PKAc $\alpha$, Rac1, or Rac1V12 expression vector. I, Primary hippocampal neurons were transfected as in $\boldsymbol{H}$. Represented images of GFP-stained neurons are shown on the left. J, Primary cortical neurons cotransfected with the EGFP and DDX3 or empty expression vectors were mock or $\mathrm{H} 89$ treated for $24 \mathrm{~h}$. $\boldsymbol{K}$, Primary cortical neurons at DIV2 were mock or FK treated for $24 \mathrm{~h}$. Cell lysates were subjected to immunoprecipitation (IP) with anti-Tiam2 and immunoblotting for Tiam2 and phospho-PKA substrates. Error bars indicate SE.

PKAc $\alpha$ protein expression in primary neurons, we transfected siD\#1 and the pEGFP expression vector in DIV6 cortical neurons and performed coimmunostaining of GFP with PKAc $\alpha$ or Rac1 at DIV9. DDX3 knockdown decreased the levels of PKAc $\alpha$ and Racl by $\sim 50$ and $\sim 40 \%$, respectively (Fig. $5 B$ ), supporting the direct role of DDX3 in expression of those two factors in primary neurons.

Activation of PKA-Rac1 signaling in primary neurons

To examine whether DDX3 knockdown also decreases Rac1 activity in cortical neurons, we transfected siRNA into cortical neuron using high efficient Magnetofectamine. Transfection of siD\#1 decreased DDX3 and Rac1 protein expression and robustly abolished Racl activation (Fig. 5C). Next, we evaluated the involvement of the PKA-Racl signaling pathway in cortical neurite outgrowth. Forskolin slightly increased the neurite length of cortical neurons, whereas H89 almost completely abolished neurite outgrowth of both control and forskolin-treated cortical neurons (Fig. 5D). Consistent with the results of N2A cells, forskolin treatment induced Racl activation while $\mathrm{H} 89$ disrupted the activation (Fig. 5E). Overexpression of Rac1N17 reduced the neurite length by $\sim 30 \%$, even in the presence of forskolin (Fig. $5 F$ ), indicating that Rac1 is a critical mediator of PKA-mediated neurite outgrowth.

Next, we tested whether DDX3 modulates cortical neurite outgrowth via the PKA-Rac1 pathway. We transfected siD\#1 in 
DIV0 cortical neurons and observed, as above, that the neurite length of transfected cells decreased significantly at DIV2. Neither overexpression of Racl nor forskolin treatment was sufficient to rescue neurite outgrowth. Nevertheless, a combination of ectopic Racl and forskolin fully restored the neurite length of DDX3 knockdown neurons (Fig. 5G), indicating that DDX3 knockdown disrupted PKA-Racl signaling in neurons, as observed in N2A cells. We also individually or concomitantly expressed PKAc $\alpha$ and Rac1 or Rac1V12 in control or DDX3 knockdown cortical neurons. The results showed that the elevation of either PKAc $\alpha$ and Rac1 level or Racl activity was sufficient to compensate neurite outgrowth in DDX3 knockdown cortical neurons (Fig. 5H). Similar results were replicated in hippocampal neurons (Fig. 5I).

Although FLAG-DDX3 was transiently overexpressed in cortical neurons, the neurite length of transfected neurons was not significantly increased (Fig. 5J, compare DDX3 with vector in the absence of H89). We suspected that a high dose of DDX3 in transiently transfected neurons has noxious effects, such as translation suppression (Shih et al., 2008), and therefore compromises neuronal function. Nevertheless, we observed that DDX3 overexpression could neutralize the suppressive effect of H89 (Fig. $5 J)$. Therefore, DDX3-activated PKAc $\alpha$ and Rac1 expression may strengthen PKA-Racl signaling to promote neurite outgrowth of primary neurons in response to increased cAMP level and PKA activation. Finally, we demonstrated that forskolin treatment in cortical neurons also induced PKA-mediated phosphorylation of Tiam2, which may subsequently lead to Rac1 activation (Fig. $5 K$ ).

\section{DDX3-mediated signaling in dendrite morphogenesis}

The data showing that the level of DDX3 protein peaked during DIV6-DIV9 in hippocampal neurons implied its potential role in neurite development. We therefore transfected siD into hippocampal neurons at DIV6 and analyzed dendrite number and major dendrite length at DIV9. The results showed that DDX3 knockdown reduced the major neurite length by $\sim 40 \%$ but did not significantly affect dendrite number (Fig. 6A). The combination of Racl overexpression and forskolin treatment rescued the dendrite length in DDX3 knockdown cells, indicating the involvement of the DDX3-modulated PKA-Rac1 pathway in dendrite extension (Fig. 6A).

We also examined whether DDX3 is important for dendritic spine formation. DDX3 knockdown at DIV14 in hippocampal neurons for $3 \mathrm{~d}$ significantly decreased the density of dendritic spines (Fig. 6B). Moreover, DDX3 knockdown decreased the population of mature mushroom-shaped dendritic spines, but increased the population of immature filopodia-shaped as well as irregular dendritic spines (Fig. 6C). Racl overexpression rescued dendritic spine density but not spine maturation in DDX3 knockdown neurons (Fig. 6B, $C$, siD+R). The latter particularly required PKA activation (Fig. $6 C$, siD $+F K$, siD $+\mathrm{R}+\mathrm{FK}$ ), suggesting that DDX3-activated PKA and Rac1 expression sequentially modulates dendritic spine formation (Fig. 6D).

To evaluate DDX3 function in dendrite development in vivo, we took advantage of a DDX3-specific inhibitor, ketorolac (Samal et al., 2015). We intraperitoneally injected P14 mice with ketorolac. Immunoblotting of P24 brain showed that ketorolac treatment reduced DDX3 as well as PKAc $\alpha$ and Rac1 in the hippocampus (Fig. 6E). Golgi staining showed that pyramidal neurons in the hippocampal CA1 region exhibited shorter apical neurites as well as reduced dendritic spine density with less mature morphology upon ketorolac treatment (Fig. $6 F, G$ ). To spe- cifically validate the role of DDX3 on dendritic spine formation in vivo, we adopted AAV-mediated knockdown. The knockdown efficiency of AAV vectors encoding DDX3 shRNAs (sh1 and sh2) was verified in N2A cells (Fig. $6 H$ ). Intraventricular injection of $\mathrm{AAV}$-sh2 that harbored higher knockdown efficiency at P1 resulted in $80 \%$ lethality at P20, while AAV-sh1 and AAV-shC resulted in 20 and $0 \%$ lethality, respectively. Indeed, a high dose of ketorolac ( $>20 \mathrm{mg} / \mathrm{kg}$ ) also led to $100 \%$ lethality during P10 to $\mathrm{P} 24$. The finding indicated that a basal level of DDX3 activity in postnatal mice brain is essential for survival. We thus compared only dendritic spines between AAV-shC and AAV-sh1 hippocampus (Fig. 6I,J). Consistent with ketorolac administration, DDX3-depleted hippocampal neurons had lower dendritic spine density and exhibited less mature spine morphology (Fig. 6J). These results were thus consistent with our in vitro observations and further indicated the important role of DDX3 in dendritic spine development.

\section{DDX3 is required for localized PKA-Rac1 signaling}

We finally investigated how DDX3 regulates localized synthesis of PKAc $\alpha$ and Racl. First, we collected soma and neurites of DIV9 cortical neuronal cells grown on transwells to examine the distribution of Prkaca and Rac1 mRNAs in neurites. The neurite fraction contained a significant portion of Actb mRNA but not $D d x 3 x$ mRNA, indicating the specificity of subcellular fractionation (Fig. 7A). Moreover, both Prkaca and Racl mRNAs as well as DDX3 protein, albeit with only a small fraction, were detected in neurites (Fig. 7A). Immunoprecipitation of DDX3 demonstrated that DDX3 indeed associated with Prkaca and Rac1 mRNAs in neurites (Fig. 7A), reemphasizing the role of DDX3 in the metabolism of these two mRNAs in neurites.

Next, we subjected stable FLAG-DDX3-expressing N2A cells to subcellular fractionation. DDX3-overexpressing cells expressed increased levels of Racl and PKAc $\alpha$ proteins, as predicted. More notably, the neurite-to-soma ratios of these two proteins but not their mRNAs were increased by $20-30 \%$ compared to mock cells (Fig. $7 B$ ). In contrast, while we moderately reduced DDX3 expression using siD to partially maintain neurite outgrowth of N2A cells (see Materials and Methods), we observed that the levels of Racl and PKAc $\alpha$ proteins were significantly decreased in the remaining neurites, but only slightly decreased in the soma (Fig. 7C). Thus, DDX3 likely mediates expression of Racl and PKAc $\alpha$ proteins in neurites.

To explore how DDX3 may regulate the translation of target mRNAs in neurites, we took advantage of a dual reporter to trace both RNA localization (Rook et al., 2000) and local protein synthesis (An et al., 2008) (Fig. 7D). The reporter mRNA comprised the Rac1 5' UTR and MS2 element-containing 3' UTR; the latter allows detection of reporter mRNA localization via the binding of the nuclear-localized RFP-MS2 protein. Moreover, the reporter encoded Myr-dGFP, which can integrate into nearby membranes and is subsequently degraded in proteasomes. Immunofluorescence showed the overall GFP but not RFP signal produced from the Rac1 5' UTR reporter was decreased in DDX3 knockdown neurites (Fig. 7E). By monitoring the GFP signal in proximal and distal halves of neurites, we observed that both Rac1 5' UTR and 3' UTR increased the ratios of GFP signal in distal neurites, while DDX3 knockdown only attenuated the distal-to-proximal ratio of those reporters with the Rac1 5' UTR (Fig. $7 F$ ), indicating that DDX3-regulated local protein synthesis is $5^{\prime}$ UTR dependent. Furthermore, we observed that the GFP signal of the Rac1 5' UTR-containing reporter was more significantly reduced in the distal parts of DDX3-depleted neurites (Fig. 7G). In contrast, 
A

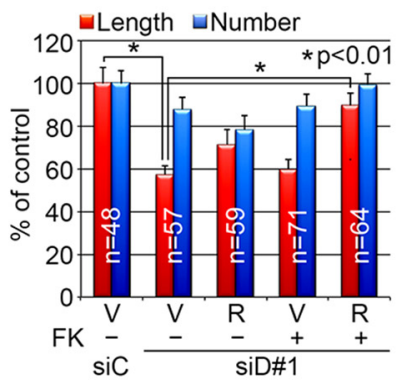

D

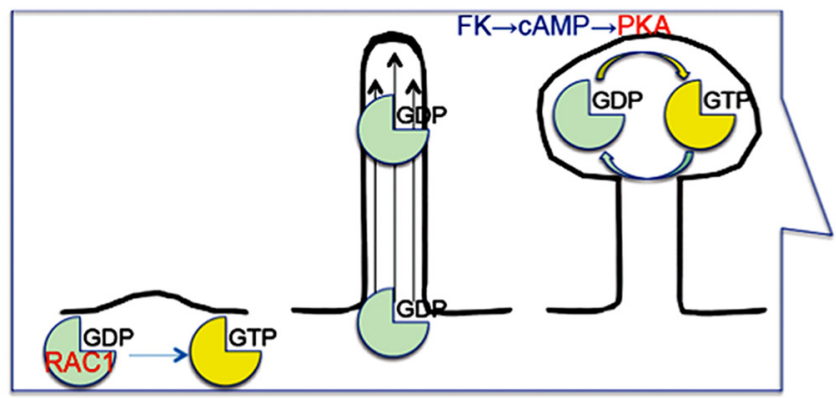

C

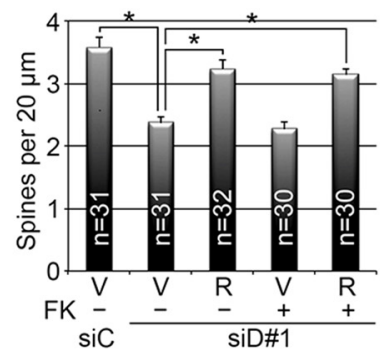

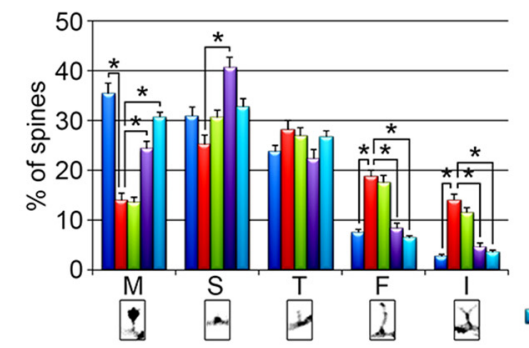

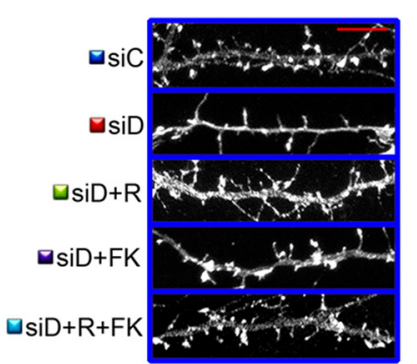

E

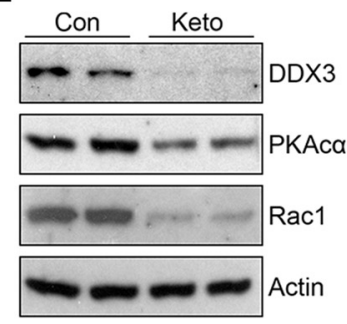

F

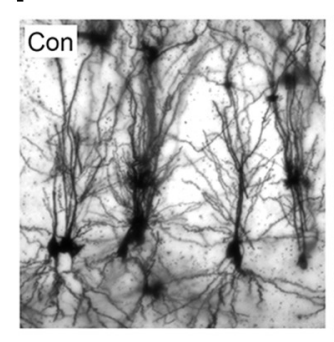

H

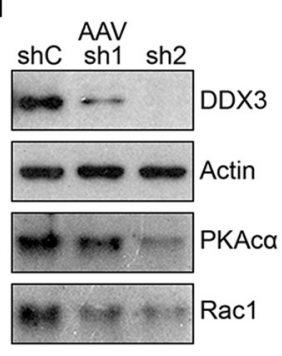

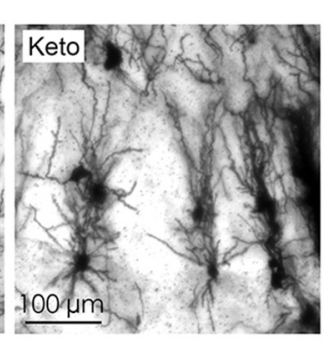

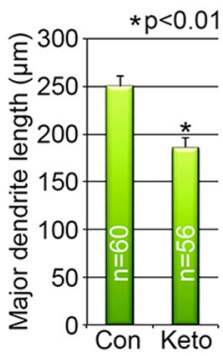

I

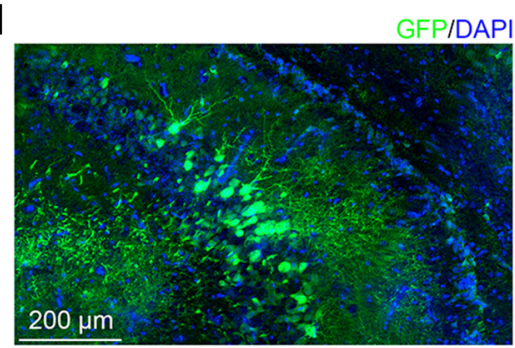

G
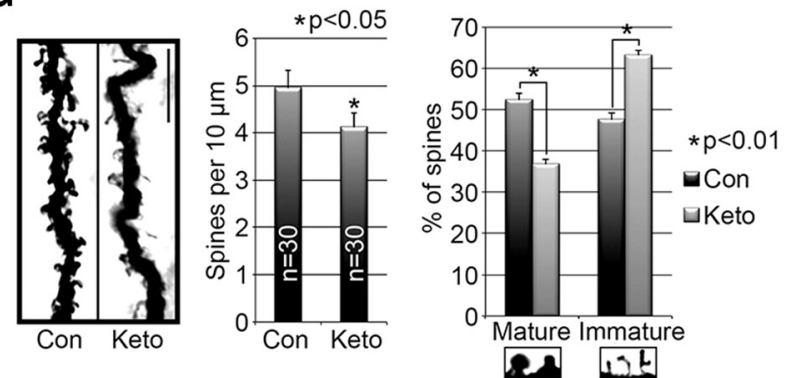

J
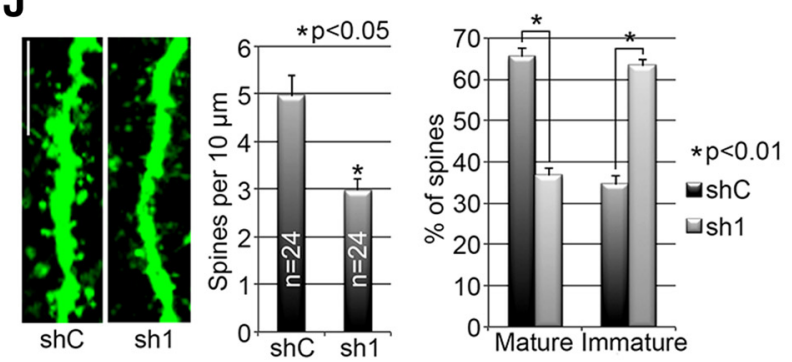

Figure 6. DDX3 modulates dendrite outgrowth and dendritic spine formation via PKA-Rac1 signaling in primary hippocampal neurons. $\boldsymbol{A}$, Primary hippocampal neurons were transfected and treated with forskolin (FK) as in Figure 5G. Immunofluorescence staining of GFP and MAP2 was performed to distinguish dendrites in transfected neurons. The bar graph shows average dendrite numbers and longest dendrite lengths of individual neurons at DIV6 + 3. B , Primary hippocampal neurons were cotransfected with pEGFP-actin and siC or siD\#1 and the empty (V) or Rac1 (R) expression vector and mock or FK treated, followed by immunofluorescence staining as in $\boldsymbol{A}$. Average dendritic spine numbers are shown in the bar graph. $\boldsymbol{C}$, Morphologies of dendritic spines in $\boldsymbol{B}$ were classified as mushroom (M), stubby (S), thin (T), filopodium (F), and irregular (I). The bar graph shows the percentages of each morphology class. The representative images of each transfection are shown at the right. D, Schematic depicting that Rac1 may promote dendritic spine formation and dendritic spine morphogenesis/maturation; the latter requires PKA activation. DDX3 regulates the translation of both PKAc $\alpha$ and Rac1 mRNAs and thereby controls the strength of PKA-Rac1 signaling for dendritic spine formation. $\boldsymbol{E}$, Hippocampal lysates from control and ketorolac-treated mice were subjected to immunoblotting analysis for DDX3, PKAc $\alpha$, Rac1, and actin. $\boldsymbol{F}$, The images (left) show Golgi staining of pyramidal neurons in the hippocampal CA1 region. The bar graph presents the average lengths of the longest apical dendrites obtained from distinguishable neurons. $\mathbf{G}$, The images show Golgi staining of apical dendritic spines in CA1 pyramidal neurons. Scale bar, $10 \mu \mathrm{m}$. The bar graphs show average spine density and percentages of mature versus immature spines for each indicated group. $\boldsymbol{H}$, N2A cells transfected with indicated AAV-shRNA were subjected to immunoblotting analysis for DDX3, actin, PKAc $\alpha$, and Rac1. I, GFP signal was detected in hippocampal neurons in P20 mice with intraventricular injection of AAV at P0. J, The images show GFP staining of dendritic spines in hippocampal neurons. Scale bar, $10 \mu \mathrm{m}$. The bar graphs show average spine density and percentages of mature versus immature spines for each indicated group. Error bars indicate SE.

DDX3 knockdown affected neither GFP nor RFP signals of the control reporter in neurites (Fig. 7E). These results indicated that DDX3 specifically activated the translation of the reporter containing the Rac1 5' UTR in neurites.
To further demonstrate that the Rac1 5' UTR-GFP reporter expression in neurites involves local translation, we performed FRAP. The GFP fluorescence from this reporter was recovered faster in the neurite terminus of the control than DDX3 knock- 
A

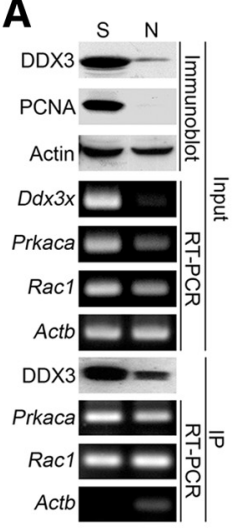

B

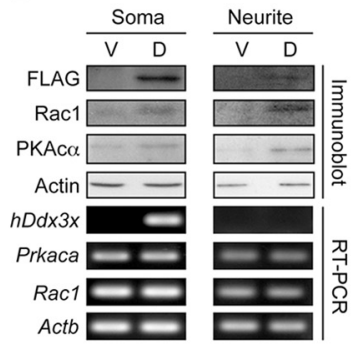

C

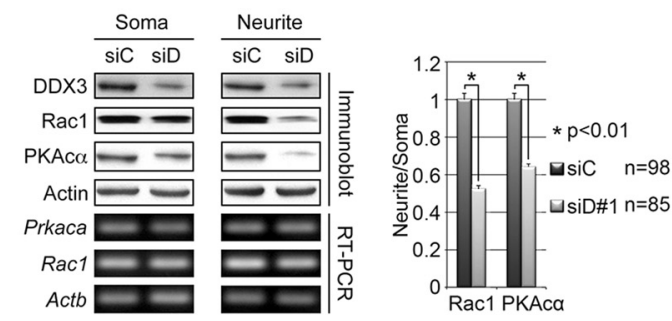

D

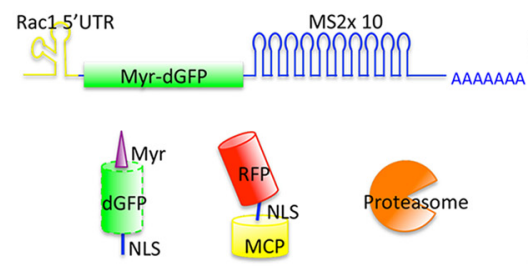

$\mathbf{F}$

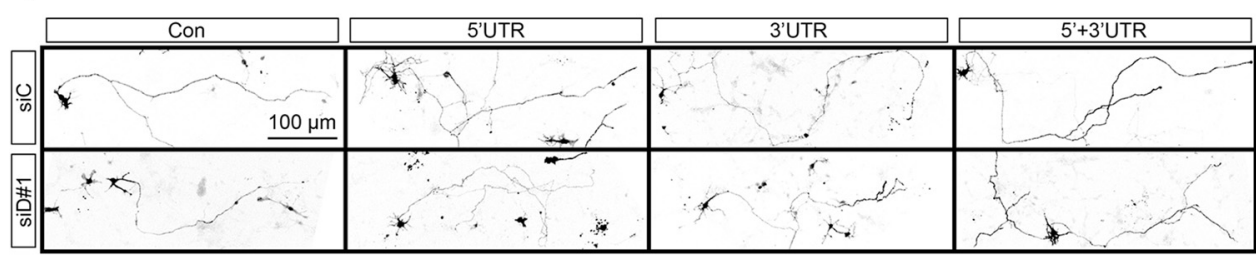

G

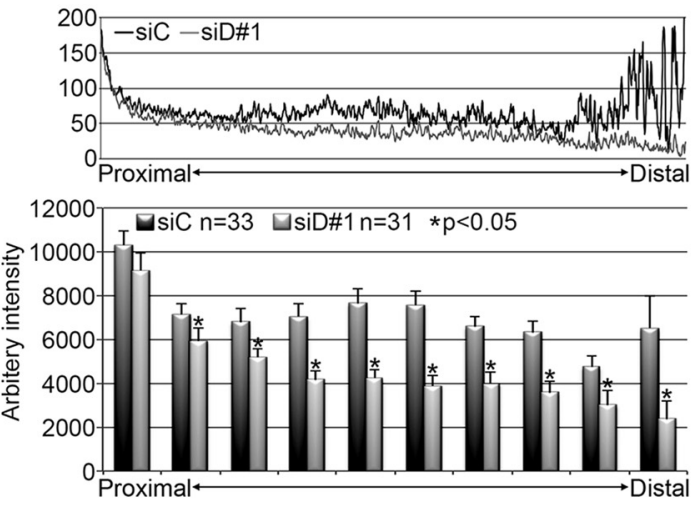

H

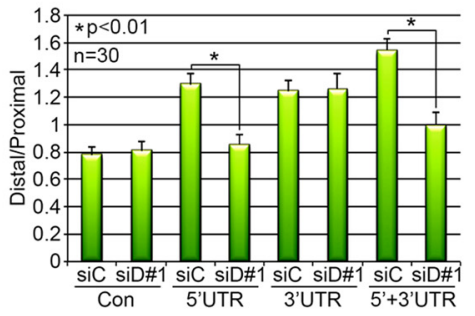

E

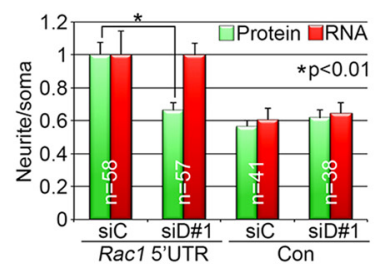

Figure 7. DDX3 is involved in local synthesis of PKAc $\alpha$ and Rac1. A, Cortical neurons were cultured in transwell inserts (1 $\mu \mathrm{m}$ pores) for $3 \mathrm{~d}$. Soma (S) and neurite (N) lysates were respectively isolated from top and bottom compartments and subjected to immunoprecipitation (IP) with anti-DDX3. Protein and RNA collected from both input and IP were analyzed with immunoblotting and RT-PCR, respectively. B, Left, Mock (V, Vector) or high-level FLAG-DDX3-expressing (D, DDX3) stable N2A cells (see Fig. 4E) were cultured in transwell inserts and treated with forskolin for $24 \mathrm{~h}$. Protein and RNA from both soma and neurites were analyzed by immunoblotting and RT-PCR, respectively. Right, Quantification of immunofluorescence intensity of PKAc $\alpha$ and Rac1 in stable cells. The bar graph shows the relative neurite/soma intensity of DDX3-expressing versus mock cells. $\boldsymbol{C}$, The experiment and analysis were as in $\boldsymbol{B}$ except that siRNA-transfected N2A cells were used. The bar graph shows the relative neurite/soma intensity of DDX3-expressing versus mock cells. D, The diagram depicts the design of RFP-MCP and Myr-dGFP to monitor local Myr-dGFP synthesis and localization of Myr-dGFP-MS2 mRNA in neurons. E, Cortical neurons were cotransfected with siRNA (siC or siD\#1), the control (Con) or Rac1 15' UTR-containing Myr-dGFP reporter, and pRFP-MCP at DIV1 and subjected to fluorescence quantification at DIV3. The bar graph shows the neurite-to-soma ratios of the Myr-dGFP protein and Myr-dGFP-MS2 mRNA, as indicated by GFP (green bar) and RFP (red bar) fluorescence, respectively. F, Cortical neurons were cotransfected with siRNA (siC or siD\#1) and the control (Con), Rac1 5' UTR, Rac1 3' UTR, or both Rac1 5' and 3' UTR-containing Myr-dGFP reporter at DIV1 and subjected to fluorescence quantification at DIV3. The bar graph shows distal half to proximal half ratios of the Myr-dGFP protein. G, Cortical neurons were cotransfected with siC or siD\#1 and the Rac15' UTR-containing Myr-dGFP reporter at DIV1. Fluorescence intensity was quantified along the major neurites ranging from 150 to $450 \mu \mathrm{m}$ at DIV3 (top). The bar graph shows the intensity of equally divided regions ( $45 \mu \mathrm{m}$ each) from the proximal to distal ends (bottom). $\boldsymbol{H}$, Neurons were transfected as in $\boldsymbol{F}$ and subjected to FRAP. A set of siC-transfected cells was treated with cycloheximide (CHX) for $30 \mathrm{~min}$. Images show neurite terminals before (-) and immediately after bleaching ( 0 ), and at 4 and 10 min after bleaching. The graph shows the average fluorescence intensity of siC, siD\#1, and siC + CHX neurite terminals, respectively. Error bars indicate SE. 
down neurons (Fig. 7H) . Cycloheximide abolished such GFP fluorescence recovery, supporting the role of translation in Rac1 5' UTR-GFP expression at neurite tips (Fig. $7 H$ ). Collectively, our results indicated that DDX3 promotes the translation of target mRNAs in neurites and that local upregulation of the DDX3 targets Racl and PKAc $\alpha$ facilitates neurite outgrowth and dendritic spine formation.

\section{Discussion}

We previously reported that DDX3 is essential for efficient translation of Rac1 mRNA, and DDX3-mediated Racl expression sustains the Wnt- $\beta$-catenin signaling pathway that promotes cancer cell invasion (Chen et al., 2015). Our present study presents evidence that DDX3 regulates the translation of both Prkaca and Racl mRNAs in neurons and therefore maintains the PKA-Rac1 signaling axis at neurite terminals for both neurite outgrowth and dendritic spine formation.

\section{DDX3 promotes translation via structured 5' UTR elements} We and others have demonstrated that DDX3 is essential for efficient translation of specific mRNAs with complicated 5' UTRs (Lai et al., 2008, 2010; Soto-Rifo et al., 2012; Chen et al., 2015). Moreover, DDX3 interacts and/or colocalizes with eIF4F components (Lai et al., 2008; Soto-Rifo et al., 2012). DDX3/Ded1p may facilitate RNA unwinding during ribosomal scanning of mRNAs or induce local separation of structured regions to facilitate cap recognition and eIF4A-catalyzed unwinding (Marsden et al., 2006; Lai et al., 2008; Soto-Rifo et al., 2012). We previously determined a DDX3-responsive region in the Rac1 5' UTR that contains two extended RNA duplexes (Chen et al., 2015), and in our present study we found that this structural feature exists in the 5' UTR of Prkaca (Fig. 3). We thus deduced that DDX3 may recognize common RNA structural and/or sequence elements in the $5^{\prime}$ UTR to facilitate translation. Moreover, the notions that the DDX3-S382L mutant with partial RNA helicase activity failed to activate translation of Racl and Prkaca mRNAs (Fig. 3), whereas it could sustain local RNA unwinding (SotoRifo et al., 2012), suggest that DDX3 can assist translation via different mechanisms.

\section{DDX3 promotes translation in neuronal growth cones}

Localized translational control in RNA granules is important for spatial and temporal protein expression in polarized cells (Gavis et al., 2007; Holt and Schuman, 2013). The Drosophila RNA helicase Me31B (DDX6 homolog) has been found in RNA granules, but it functions to suppress the translation of certain synaptic mRNAs in the dendrites of hippocampal neurons (Hillebrand et al., 2010). Indeed, human DDX6 also functions to suppress translation during erythrocyte differentiation (Naarmann et al., 2010). Besides, RNA helicases have been shown to regulate the activity or direct dendritic localization of miRNAs in neuronal cells, but in that context they also suppress translation (Bicker et al., 2013; Nicklas et al., 2015). In contrast, we show here that DDX3 positively regulates translation of target mRNAs in neurites (Figs. 3). Depletion of DDX3 reduced target mRNA translation particularly in neurite tips (Fig. 7). Therefore, we speculate that DDX3-associated granule factors may suppress translation before mRNPs reach the growing tip. Notably, treatment of cells with the neurotrophin BDNF increases the number and motility of DDX3 granules in hippocampal neurons (Elvira et al., 2006). The possibility of whether BDNF and/or synaptic signals control the movement of DDX3-containing granules toward neurites and/or trigger DDX3-mediated translation in neurite terminals remains to be determined.

\section{DDX3 regulates neurite outgrowth via localized translation}

Local mRNA translation plays an important role in axon guidance and synapse formation, and it also impacts neurite outgrowth (Holt and Schuman, 2013). A well-studied example is CaMKII, which plays multiple roles in neurons including neurite growth (Gavis et al., 2007). Localized translation of CaMKII $\alpha$ mRNA is regulated by translation factors and RNA binding proteins such as eEF2 and cytoplasmic polyadenylation element binding proteins through different mechanisms (Bramham and Wells, 2007). Rac family members regulate neuronal cell morphology and differentiation (Govek et al., 2005). Rac1 activation can trigger rapid neurite outgrowth in primary neurons and PC12 cells (Govek et al., 2005). The activity of Rac1 is essentially regulated by guanine exchange factors, whereas these factors can be directly or indirectly modulated by PKA (Sassone-Corsi, 2012). Although PKA plays a considerable role in neuronal outgrowth, axonal guidance, and morphogenesis (Qiu et al., 2002; Taskén and Aandahl, 2004; Tojima et al., 2011), less is known about how PKA acts via Rac1 in neuronal cells and how PKA and $\mathrm{Racl}$ expression is locally regulated in neurites. We report here that DDX3 contributes to Rac1 and PKAc $\alpha$ protein expression in neurite terminals (Figs. 5, 7), which establishes the involvement of the PKA-Racl pathway in neurite outgrowth (Figs. 2, 4). Moreover, consistent with previous reports that Racl is required for dendritic spine formation and that its activation can further promote dendritic spine enlargement/maturation (Penzes et al., 2003; Zhang et al., 2013), our results demonstrate that DDX3enhanced expression of Racl and PKAc $\alpha$ contributes to spine formation and morphogenesis in hippocampal neurons (Fig. 6). In addition, several uncharacterized DDX3 target candidates encode MAP kinases that also have secondary structures at their $5^{\prime}$ UTRs (data not shown). Localized translation of several growth cone MAP kinases contributes to neurite elongation (Feltrin et al., 2012). Therefore, DDX3 may coordinate localized translation of RNA regulons for neurite outgrowth and dendritic spine formation.

\section{DDX3-mediated fine-tuning of PKA-Rac1 signaling and neuronal development}

Neuronal cAMP levels are developmentally regulated and also influenced by a variety of environmental cues (Qiu et al., 2002). cAMP activates multiple pathways; PKA is a major downstream effector of cAMP. Nevertheless, the PKA-Racl signaling axis is largely regulated in a cell context-dependent manner and exerts various cellular effects (Sassone-Corsi, 2012; Goto et al., 2014). Here, we showed that PKA and Racl contributed to neurite outgrowth, dendrite extension, and dendritic spine formation at different stages (Figs. 5, 6). DDX3 may maintain the level of PKA-Rac1 signaling components in growth cones and dendritic spines, which increases the sensitivity of growth cones and dendritic spines to cAMP. We postulate that the activity or level of DDX3 in growing neurites may reduce the threshold for cAMP responsiveness and fine-tunes PKA signaling involved in neurite outgrowth and dendritic spine formation.

Notably, DDX3X mutations in the ATPase and helicase domains have been linked to developmental disorders and intellectual disability (ID; Rauch et al., 2012; Deciphering Developmental Disorders Study, 2015; Snijders Blok et al., 2015). We show here that administration of ketorolac, which inhibits the ATPase activity of DDX3 (Samal et al., 2015), or knockdown of DDX3 by shRNA in neonatal 
mice significantly inhibited dendritic outgrowth and/or spine formation in hippocampal neurons, supporting the critical requirement for DDX3 activity in neuronal development (Fig. 6). Moreover, our results demonstrating a role for DDX3-enhanced PKA-Racl signaling in dendrite outgrowth and dendritic spine formation (Fig. 6) imply that the PKA-Racl signaling axis might be disrupted in $D D X 3 X$-mutated ID patients. In fact, identification of mutations of CC2D1A (encoding a PKA regulatory factor) and ARHGEF6 (encoding an Rac guanine nucleotide exchange factor) in ID supports the importance of cAMP-PKA signaling and Rac1 activation in neuronal development (Al-Tawashi et al., 2012; Ramakers et al., 2012) and echoes our results. Finally, our results suggest that mutations causing defects in the DDX3-PKA-Racl signaling axis may be a potential molecular mechanism for a subset of IDs.

\section{References}

Al-Tawashi A, Jung SY, Liu D, Su B, Qin J (2012) Protein implicated in nonsyndromic mental retardation regulates protein kinase A (PKA) activity. J Biol Chem 287:14644-14658. CrossRef Medline

An JJ, Gharami K, Liao GY, Woo NH, Lau AG, Vanevski F, Torre ER, Jones KR, Feng Y, Lu B, Xu B (2008) Distinct role of long 3' UTR BDNF mRNA in spine morphology and synaptic plasticity in hippocampal neurons. Cell 134:175-187. CrossRef Medline

Ariumi Y (2014) Multiple functions of DDX3 RNA helicase in gene regulation, tumorigenesis, and viral infection. Front Genet 5:423. Medline

Bicker S, Khudayberdiev S, Weiß K, Zocher K, Baumeister S, Schratt G (2013) The DEAH-box helicase DHX36 mediates dendritic localization of the neuronal precursor-microRNA-134. Genes Dev 27:991-996. CrossRef Medline

Bramham CR, Wells DG (2007) Dendritic mRNA: transport, translation and function. Nat Rev Neurosci 8:776-789. Medline

Chen CC, Sun CP, Ma HI, Fang CC, Wu PY, Xiao X, Tao MH (2009) Comparative study of anti-hepatitis B virus RNA interference by doublestranded adeno-associated virus serotypes 7, 8, and 9. Mol Ther 17: 352-359. CrossRef Medline

Chen HH, Yu HI, Chiang WC, Lin YD, Shia BC, Tarn WY (2012) hnRNP Q regulates Cdc42-mediated neuronal morphogenesis. Mol Cell Biol 32: 2224-2238. CrossRef Medline

Chen HH, Yu HI, Cho WC, Tarn WY (2015) DDX3 modulates cell adhesion and motility and cancer cell metastasis via Rac1-mediated signaling pathway. Oncogene 34:2790-2800. CrossRef Medline

Copf T (2014) Developmental shaping of dendritic arbors in Drosophila relies on tightly regulated intra-neuronal activity of protein kinase A (PKA). Dev Biol 393:282-297. CrossRef Medline

Deciphering Developmental Disorders Study (2015) Large-scale discovery of novel genetic causes of developmental disorders. Nature 519:223-228. Medline

Elvira G, Wasiak S, Blandford V, Tong XK, Serrano A, Fan X, del Rayo Sánchez-Carbente M, Servant F, Bell AW, Boismenu D, Lacaille JC, McPherson PS, DesGroseillers L, Sossin WS (2006) Characterization of an RNA granule from developing brain. Mol Cell Proteomics 5:635-651. Medline

Feltrin D, Fusco L, Witte H, Moretti F, Martin K, Letzelter M, Fluri E, Scheiffele P, Pertz O (2012) Growth cone MKK7 mRNA targeting regulates MAP1b-dependent microtubule bundling to control neurite elongation. PLoS Biol 10:e1001439. CrossRef Medline

Gavis ER, Singer RH, Hüttelmaier S (2007) Localized translation through messenger RNA localization. In: Translational Control in Biology and Medicine (Hershey JWB, Mathews MB, Sonenberg N, eds), pp 687-717. New York: Cold Spring Harbor Laboratory Press.

Goto A, Hoshino M, Matsuda M, Nakamura T (2011) Phosphorylation of $\mathrm{STEF} / \mathrm{Tiam} 2$ by protein kinase $\mathrm{A}$ is critical for Rac1 activation and neurite outgrowth in dibutyryl cAMP-treated PC12D cells. Mol Biol Cell 22: 1780-1790. CrossRef Medline

Goto A, Kamioka Y, Matsuda M (2014) PKA modulation of Rac in neuronal cells. Front Cell Neurosci 8:321. Medline

Govek EE, Newey SE, Van Aelst L (2005) The role of the Rho GTPases in neuronal development. Genes Dev 19:1-49. CrossRef Medline

Gualdoni S, Albertinazzi C, Corbetta S, Valtorta F, de Curtis I (2007) Nor- mal levels of Racl are important for dendritic but not axonal development in hippocampal neurons. Biol Cell 99:455-464. CrossRef Medline

Heasman SJ, Ridley AJ (2008) Mammalian Rho GTPases: new insights into their functions from in vivo studies. Nat Rev Mol Cell Biol 9:690-701. CrossRef Medline

Hillebrand J, Pan K, Kokaram A, Barbee S, Parker R, Ramaswami M (2010) The Me31B DEAD-box helicase localizes to postsynaptic foci and regulates expression of a CaMKII reporter mRNA in dendrites of Drosophila olfactory projection neurons. Front Neural Circuits 4:121. Medline

Holt CE, Schuman EM (2013) The central dogma decentralized: new perspectives on RNA function and local translation in neurons. Neuron 80 : 648-657. CrossRef Medline

Iost I, Dreyfus M, Linder P (1999) Ded1p, a DEAD-box protein required for translation initiation in Saccharomyces cerevisiae, is an RNA helicase. J Biol Chem 274:17677-17683. CrossRef Medline

Kanai Y, Dohmae N, Hirokawa N (2004) Kinesin transports RNA: isolation and characterization of an RNA-transporting granule. Neuron 43:513525. CrossRef Medline

Kiebler MA, Bassell GJ (2006) Neuronal RNA granules: movers and makers. Neuron 51:685-690. CrossRef Medline

Kim JY, Ash RT, Ceballos-Diaz C, Levites Y, Golde TE, Smirnakis SM, Jankowsky JL (2013) Viral transduction of the neonatal brain delivers controllable genetic mosaicism for visualising and manipulating neuronal circuits in vivo. Eur J Neurosci 37:1203-1220. CrossRef Medline

Kuhn TB, Meberg PJ, Brown MD, Bernstein BW, Minamide LS, Jensen JR, Okada K, Soda EA, Bamburg JR (2000) Regulating actin dynamics in neuronal growth cones by ADF/cofilin and rho family GTPases. J Neurobiol 44:126-144. Medline

Lai MC, Lee YH, Tarn WY (2008) The DEAD-box RNA helicase DDX3 associates with export messenger ribonucleoproteins as well as tipassociated protein and participates in translational control. Mol Biol Cell 19:3847-3858. CrossRef Medline

Lai MC, Chang WC, Shieh SY, Tarn WY (2010) DDX3 regulates cell growth through translational control of cyclin E1. Mol Cell Biol 30:5444-5453. CrossRef Medline

Lee CS, Dias AP, Jedrychowski M, Patel AH, Hsu JL, Reed R (2008) Human DDX3 functions in translation and interacts with the translation initiation factor eIF3. Nucleic Acids Res 36:4708-4718. CrossRef Medline

Liu-Yesucevitz L, Bassell GJ, Gitler AD, Hart AC, Klann E, Richter JD, Warren ST, Wolozin B (2011) Local RNA translation at the synapse and in disease. J Neurosci 31:16086-16093. CrossRef Medline

Marsden S, Nardelli M, Linder P, McCarthy JE (2006) Unwinding single RNA molecules using helicases involved in eukaryotic translation initiation. J Mol Biol 361:327-335. CrossRef Medline

Naarmann IS, Harnisch C, Müller-Newen G, Urlaub H, Ostareck-Lederer A, Ostareck DH (2010) DDX6 recruits translational silenced human reticulocyte 15-lipoxygenase mRNA to RNP granules. RNA 16:2189-2204. CrossRef Medline

Nicklas S, Okawa S, Hillje AL, González-Cano L, Del Sol A, Schwamborn JC (2015) The RNA helicase DDX6 regulates cell-fate specification in neural stem cells via miRNAs. Nucleic Acids Res 43:2638-2654. CrossRef Medline

Penzes P, Beeser A, Chernoff J, Schiller MR, Eipper BA, Mains RE, Huganir RL (2003) Rapid induction of dendritic spine morphogenesis by transsynaptic ephrinB-EphB receptor activation of the Rho-GEF kalirin. Neuron 37:263-274. CrossRef Medline

Qiu J, Cai D, Dai H, McAtee M, Hoffman PN, Bregman BS, Filbin MT (2002) Spinal axon regeneration induced by elevation of cyclic AMP. Neuron 34:895-903. CrossRef Medline

Ramakers GJ, Wolfer D, Rosenberger G, Kuchenbecker K, Kreienkamp HJ, Prange-Kiel J, Rune G, Richter K, Langnaese K, Masneuf S, Bösl MR, Fischer KD, Krugers HJ, Lipp HP, van Galen E, Kutsche K (2012) Dysregulation of Rho GTPases in the alphaPix/Arhgef6 mouse model of $\mathrm{X}$-linked intellectual disability is paralleled by impaired structural and synaptic plasticity and cognitive deficits. Hum Mol Genet 21:268-286. CrossRef Medline

Rauch A, Wieczorek D, Graf E, Wieland T, Endele S, Schwarzmayr T, Albrecht B, Bartholdi D, Beygo J, Di Donato N, Dufke A, Cremer K, Hempel M, Horn D, Hoyer J, Joset P, Röpke A, Moog U, Riess A, Thiel CT, et al. (2012) Range of genetic mutations associated with severe nonsyndromic sporadic intellectual disability: an exome sequencing study. Lancet 380:1674-1682. CrossRef Medline 
Rook MS, Lu M, Kosik KS (2000) CaMKIIalpha 3' untranslated regiondirected mRNA translocation in living neurons: visualization by GFP linkage. J Neurosci 20:6385-6393. Medline

Samal SK, Routray S, Veeramachaneni GK, Dash R, Botlagunta M (2015) Ketorolac salt is a newly discovered DDX3 inhibitor to treat oral cancer. Sci Rep 5:9982. CrossRef Medline

Sassone-Corsi P (2012) The cyclic AMP pathway. Cold Spring Harb Perspect Biol 4:a011148. Medline

Sharma D, Jankowsky E (2014) The Ded1/DDX3 subfamily of DEAD-box RNA helicases. Crit Rev Biochem Mol Biol 49:343-360. CrossRef Medline

Shih JW, Tsai TY, Chao CH, Wu Lee YH (2008) Candidate tumor suppressor DDX3 RNA helicase specifically represses cap-dependent translation by acting as an eIF4E inhibitory protein. Oncogene 27:700-714. CrossRef Medline

Sinnamon JR, Czaplinski K (2011) mRNA trafficking and local translation: the Yin and Yang of regulating mRNA localization in neurons. Acta Biochim Biophys Sin (Shanghai) 43:663-670. CrossRef

Snijders Blok L, Madsen E, Juusola J, Gilissen C, Baralle D, Reijnders MR, Venselaar H, Helsmoortel C, Cho MT, Hoischen A, Vissers LE, Koemans TS, Wissink-Lindhout W, Eichler EE, Romano C, Van Esch H, Stumpel C, Vreeburg M, Smeets E, Oberndorff K, et al. (2015) Mutations in DDX3X are a common cause of unexplained intellectual disability with genderspecific effects on Wnt signaling. Am J Hum Genet 97:343-352. CrossRef Medline

Soto-Rifo R, Ohlmann T (2013) The role of the DEAD-box RNA helicase DDX3 in mRNA metabolism. Wiley Interdiscip Rev RNA 4:369-385. CrossRef Medline

Soto-Rifo R, Rubilar PS, Limousin T, de Breyne S, Décimo D, Ohlmann T
(2012) DEAD-box protein DDX3 associates with eIF4F to promote translation of selected mRNAs. EMBO J 31:3745-3756. CrossRef Medline

Tashiro A, Yuste R (2004) Regulation of dendritic spine motility and stability by Racl and Rho kinase: evidence for two forms of spine motility. Mol Cell Neurosci 26:429-440. CrossRef Medline

Taskén K, Aandahl EM (2004) Localized effects of cAMP mediated by distinct routes of protein kinase A. Physiol Rev 84:137-167. CrossRef Medline

Tojima T, Hines JH, Henley JR, Kamiguchi H (2011) Second messengers and membrane trafficking direct and organize growth cone steering. Nat Rev Neurosci 12:191-203. CrossRef Medline

Woo S, Gomez TM (2006) Racl and RhoA promote neurite outgrowth through formation and stabilization of growth cone point contacts. J Neurosci 26:1418-1428. CrossRef Medline

Yang Q, Jankowsky E (2005) ATP- and ADP-dependent modulation of RNA unwinding and strand annealing activities by the DEAD-box protein DED1. Biochemistry 44:13591-13601. CrossRef Medline

Yedavalli VS, Neuveut C, Chi YH, Kleiman L, Jeang KT (2004) Requirement of DDX3 DEAD box RNA helicase for HIV-1 Rev-RRE export function. Cell 119:381-392. CrossRef Medline

Yusta B, Ortiz-Caro J, Pascual A, Aranda A (1988) Comparison of the effects of forskolin and dibutyryl cyclic AMP in neuroblastoma cells: evidence that some of the actions of dibutyryl cyclic AMP are mediated by butyrate. J Neurochem 51:1808-1818. CrossRef Medline

Zhang XL, Pöschel B, Faul C, Upreti C, Stanton PK, Mundel P (2013) Essential role for synaptopodin in dendritic spine plasticity of the developing hippocampus. J Neurosci 33:12510-12518. CrossRef Medline 